Estudios sobre armas antiguas, arte militar $\mathrm{y}$ vida cultural en oriente y occidente XXXV (2015), pp. 35-60

ISSN: 0436-029X

doi: 10.3989/gladius.2015.0003

\title{
ALAMARES METÁLICOS: UN SISTEMA DE CIERRE PARA CORREAJES ECUESTRES EN LA PROTOHISTORIA DE LA PENÍNSULA IBÉRICA
}

\author{
METAL TOGGLES: A BUCKLE SYSTEM FOR EQUESTRIAN \\ HARNESSES ON IBERIAN IRON AGE
}

POR

JAVIER JIMÉNEZ ÁVILA*

\section{Resumen - Abstract}

Se replantea la función de unos característicos objetos metálicos aparecidos en distintos contextos arqueológicos de la Edad del Hierro peninsular que han venido siendo interpretados, por parte de la investigación española, como camas laterales de bocados de caballo. Ni su forma, ni sus contextos, ni la existencia de abundantes paralelos europeos, que nunca han sido referidos en los estudios hispánicos y que son objeto de otras lecturas, avalan esta interpretación. En su lugar se propone su uso como alamares o elementos integrantes de los sistemas de cierre para correajes ecuestres. Existe evidencia iconográfica de este uso en la estatuaria zoomorfa ibérica.

There's a group of metallic fits which are present in many Iberian Iron Age contexts that are being usually interpreted as horse bits by the Spanish research. However, neither their morphology, nor their archaeological contexts make credible these interpretation. In addition, there are a lot of European similar findings, mainly from chariot tombs from the Hallstatt and La Tène Cultures, which are interpreted as closing yoke pieces (toggles) and which can indicate the true function for these Spanish findings. Some iconographical evidence from a horse stone sculpture coming from Andalusia could confirm this use in the Late Iberian Iron Age.

\section{Palabras Clave - Keywords}

Península Ibérica; Edad del Hierro; Atalajes ecuestres; Escultura ibérica; Cultura de Hallstatt.

Iberian Archaeology; Iron Age; Horse harness; Iberian Sculpture; Hallstatt Culture.

\section{INTRODUCCIÓN}

En las excavaciones de la necrópolis celtibérica del Altillo de Cerropozo (Atienza, Guadalajara), realizadas en 1929, y más concretamente en las tumbas designadas con los números 15 y 16, descubrió J. Cabré unos objetos metálicos formados por un cuerpo prismático horadado por una ranura longitudinal y dotados de unos apéndices curvados a modo de brazos. A partir de esta morfología fueron interpretados como camas laterales de bocados de caballo (Cabré, 1930: 23 y 26). Posteriores hallazgos de similar formato, localizados en distintos yacimientos peninsulares de la Edad del Hierro, han sido interpretados mayoritaria, aunque no unánimemente, en la misma línea funcional. En este trabajo pretendo replantear esta funcionalidad con 
argumentos basados en la inadecuación tipológica de estos utensilios a su uso como bocados, en el escaso apoyo que ofrecen a esta lectura los contextos en que aparecen y, sobre todo, en la existencia de abundantes paralelos europeos que nunca han sido traídos a colación y que son objeto de otras interpretaciones más verosímiles. Además, se añaden argumentos iconográficos, dentro de la plástica ibérica, que permiten refrendar las nuevas propuestas funcionales que aquí se hacen para ellos. La nueva lectura de estos elementos plantea una serie de sugerencias y de problemas referentes a su tipología, a su cronología y a las relaciones culturales de los contextos en que aparecen.

\section{LOS HALLAZGOS DE LAS TUMBAS 15 Y 16 DE ATIENZA: PRIMERAS INTERPRE- TACIONES}

Las tumbas 15 y 16 de la necrópolis atiencina del Altillo de Cerropozo constituyen dos de las sepulturas más ricas de las excavadas por Cabré en este cementerio celtibérico. Se trata de dos típicas tumbas de guerrero que, a una nutrida colección de armas de hierro defensivas y ofensivas, unen característicos conjuntos de arreos de caballo, adornos corporales de bronce y contenedores cinerarios cerámicos (Fig. 1).

Sobre los elementos que aquí nos interesan, presentes en ambos conjuntos por partida doble, existen ciertas imprecisiones que afectan tanto a su naturaleza cuanto a su función. Para

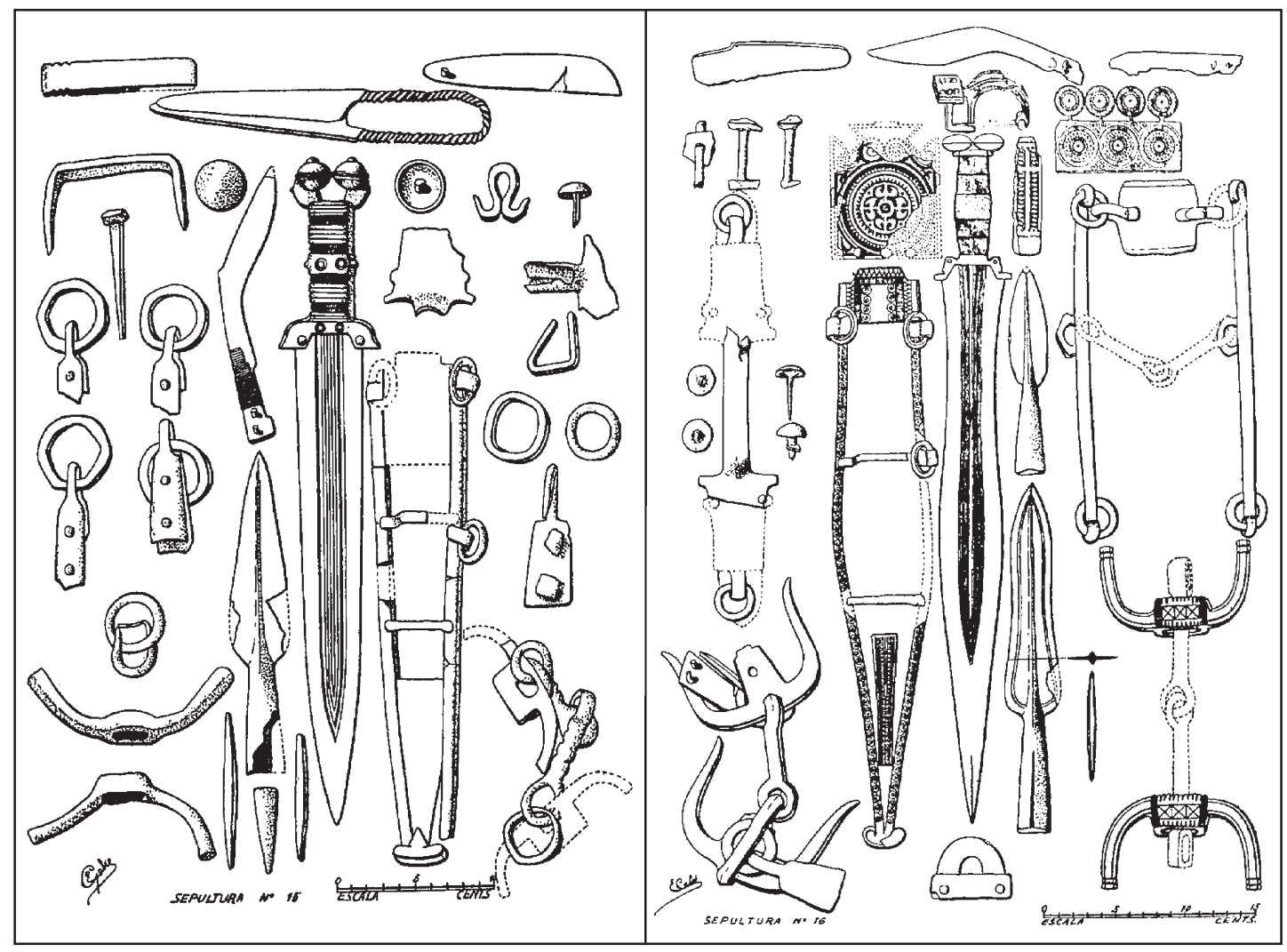

Figura 1. Ajuares metálicos de las sepulturas 15 y 16 de la necrópolis celtibérica del Altillo de Cerropozo (Atienza), s. Cabré, 1930. 
las de la tumba 15 señala Cabré que se trata de "dos piezas gemelas entre sí, pero de diverso tamaño, una de ellas de bronce, con un taladro rectangular en su centro, de sección circular y afectando la forma de un tercio de círculo, de las que se desconoce su uso indudable, suponiendo pertenecieron a las camas de un bocado, a lo que añadiremos, además, que únicamente se han encontrado ejemplares parecidos a ellos, pero de bronce, en la necrópoli de La Requijada de Gormaz (Soria)" (Cabré, 1930: 23). Sobre los de la tumba 16 indica que se trata de “... las dos camas de otro, a la vez único y extraordinario bocado, de 0,11 y 0,11 1 1/2 metros de anchura, del que se ignora la forma total de los eslabones que los unían, que afecta forma de arco casi de medio punto, tienen sección hexagonal y se decoran con dos ranuras circulares en cada extremo y una serie de muescas en torno del perímetro rectangular de su parte central, cuyo recuadro, además, encierra otro rectángulo subdividido en tres zonas con líneas diagonales, todo ello hecho a fuerza de lima y en muy buen estado de conservación" (Cabré, 1930: 26). El hecho de que no se indique el material sobre el que se realizan las piezas sugiere que fueran de hierro, pues lo normal en las descripciones de esta memoria es que se omita este dato cuando se trata de objetos realizados sobre este metal, especificándose, en cambio, cuando están fabricados en bronce

En el caso de los ejemplares de la tumba 16, el dibujo presentado se complementa, además, con la inclusión, en línea discontinua, del supuestamente perdido filete que, por su perfil, recuerda a dos frenos inéditos hallados por el Marqués de Cerralbo en la necrópolis de Navafría (Clares, Guadalajara) ${ }^{1}$ y que, curiosamente, constituyen dos de los extraños ejemplares de bocados celtibéricos realizados en bronce. De este modo, respecto de estos dos ejemplares, se disipan las dudas funcionales que podrían caber en torno a los de la tumba 15 (Fig. 2.1).

Lo cierto es que las dos tumbas presentaban los verdaderos bocados, ambos de hierro, en un estado bastante completo y reconocible. El de la número 15 está compuesto por un filete articulado que en un lateral se une a una cama laminar de silueta curvada y en el otro a una anilla. El de la número 16, más completo, preserva las dos camas, también curvadas (liriformes, en la terminología de Cabré), dos anillas y dos agarradores. Este último, además, se complementaría con una cabezada metálica de quijeras y serretón que Cabré identifica como un bocado distinto (Fig. 1).

Probablemente la similitud entre las camas de estos bocados y los elementos curvos que las acompañaban en estas sepulturas y que aquí nos interesan, fuera lo que indujera a Cabré a asimilar funcionalmente unas y otros; así como, tal vez, la errónea identificación como bocado de la cabezada metálica de la tumba 16, que le llevaría a considerar la posibilidad de que hubiera más de un freno por tumba, fenómeno excepcional en las necrópolis de la Segunda Edad del Hierro, tanto del área celtibérica como vetona (Schüle, 1969; Lorrio, 1997; Kurtz, 1987; Cabré et alii, 1950).

Sea como fuere, esta atribución funcional ha sido después sostenida por los distintos autores que han tratado este tipo de piezas de brazos curvados y aplicada, posteriormente, a unas piezas similares de brazos rectos, como seguidamente tendremos ocasión de comprobar.

1 MAN 1940/27/CL/1564 y 1940/27/CL/1565. 

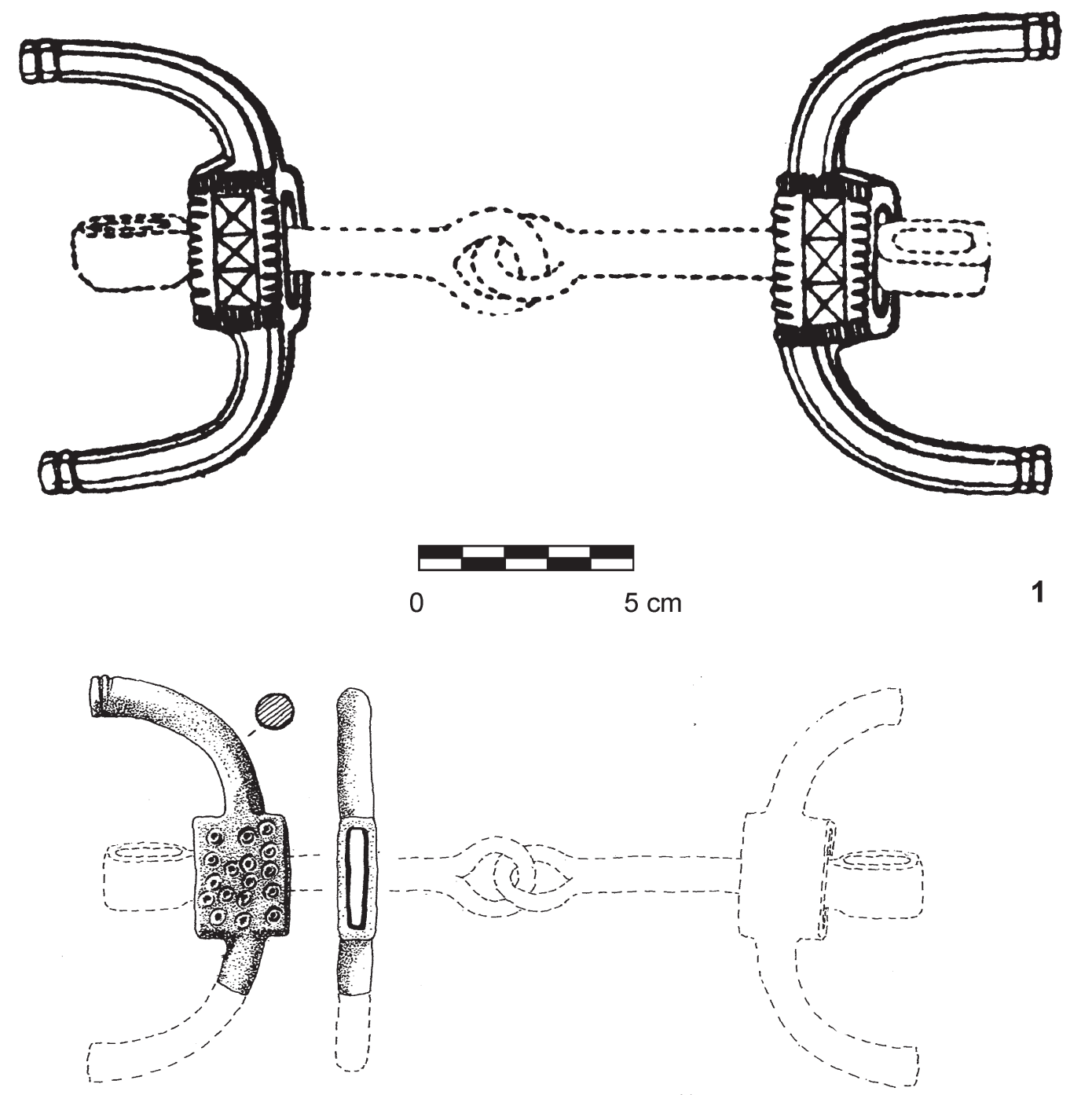

Figura 2. Objetos de brazos curvos reconstruidos como componentes de bocados. 1. Necrópolis del Altillo de Cerropozo (Atienza), s. Cabré, 1930; 2. De las inmediaciones de El Raso de Candeleda (Ávila), s. Fernández Gómez, 1986.

\section{OTROS HALLAZGOS DE LA PENÍNSULA IBÉRICA}

Aunque no es el objetivo de este trabajo la realización de un catálogo exhaustivo de los objetos que aquí se tratan, conviene citar algunos de los ya conocidos, de cara a poner de manifiesto su desarrollo geográfico y cronológico en el ámbito de la Protohistoria peninsular, así como a argumentar la propuesta funcional que aquí realizo y que los desvincula de su relación con bocados de caballo, sin por ello separarlos de la esfera de los atalajes ecuestres. Esto podría servir, de paso, para hacer una llamada a los museos y colecciones a revisar entre sus fondos inéditos la existencia de elementos similares que muy posiblemente existan. 
El primer hallazgo de esta serie que debe referirse es el procedente de la mal conocida necrópolis de Haza del Arca (Uclés, Cuenca), publicado incluso con anterioridad a los de Atienza. Se trata de un ejemplar de bronce, con decoración troquelada (Fig. 3.1) que P. Quintero

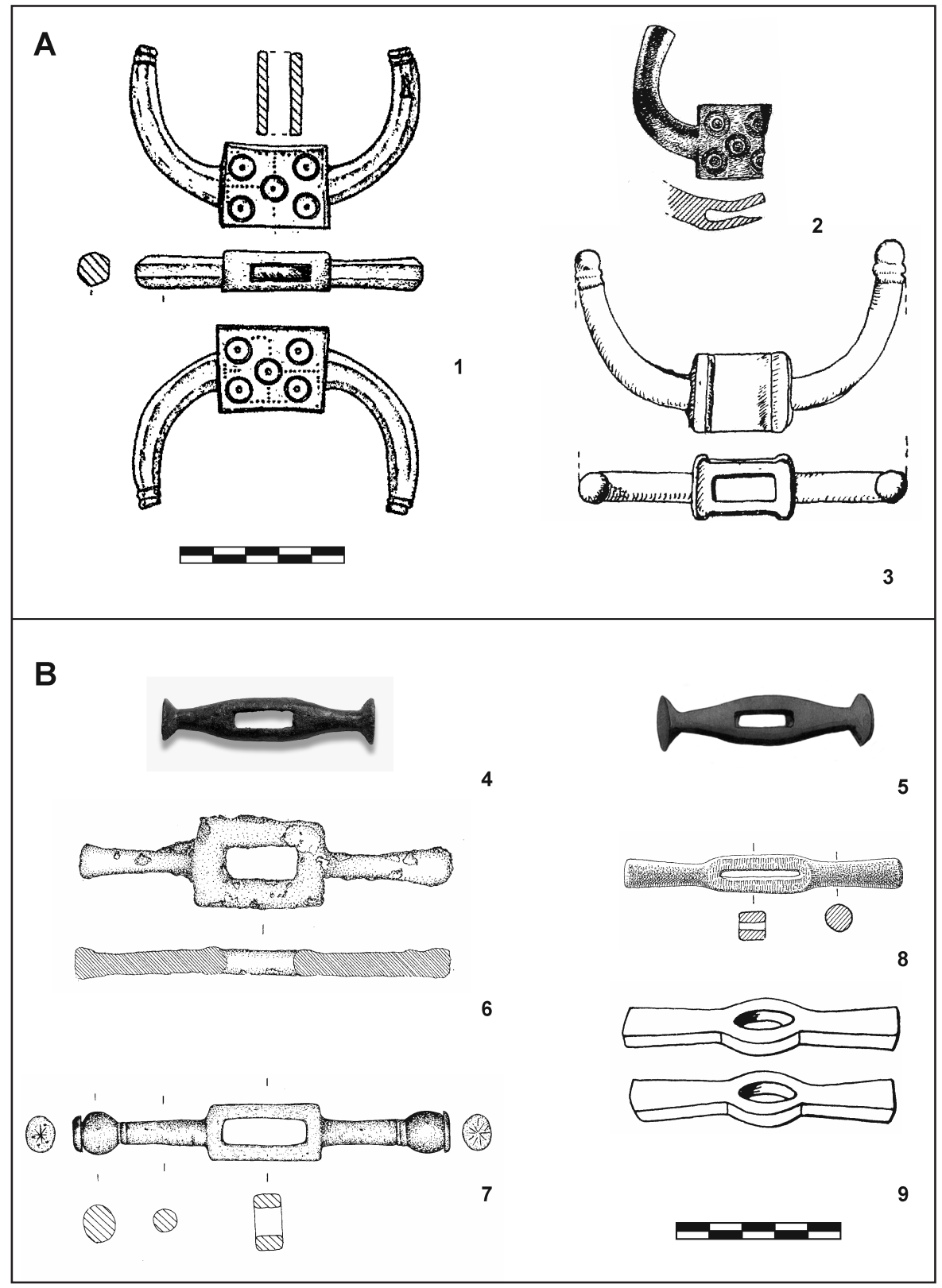

Figura 3. A: Objetos de bronce de brazos curvos: 1. Necrópolis de Uclés, s. Lorrio, 2007; 2. Necrópolis de Las Ruedas, s. Sanz 1997; 3. El Cigarralejo t. 103, s. Cuadrado, 1987; B: Objetos de brazos rectos: 4. Museo Arqueológico Provincial de Sevilla (Acebuchal ?), Foto M. García Pérez; 5. Necrópolis de Carmona, s. Bonsor, 1931; 6. Cancho Roano, s. Maluquer, 1981; 7. Cancho Roano, dibujo Mar Alfaro; 8. Tumba 17 de La Joya, s. Garrido y Orta, 1978; 9. Tumba LX de la zona III de La Osera, dibujo de E. Cabré en Schüle, 1969. 
identifica con el guardamanos de una espada (Quintero, 1913: 121). La escasa resonancia de este yacimiento, cuyos materiales han venido siendo atribuidos a Segobriga hasta los recientes trabajos de A. Lorrio (2007), hizo que pasaran desapercibidos, incluso, al propio Cabré. De hecho, los únicos paralelos que este investigador refiere para los cuatro objetos de Atienza son los dos ejemplares de bronce hallados por G. Morenas de Tejada en la necrópolis de La Requijada de Gormaz (Soria), prácticamente inéditos hasta la actualidad² (Cabré, 1930: 23). Otros hallazgos del área celtibérica se han producido en Carratiermes (Montejo de Tiermes, Soria), donde aparecen dos ejemplares de hierro en los depósitos de las tumbas 3 y 9. Su estudio los sitúa entre los bocados de caballo, señalándose algunos inconvenientes técnicos a este propósito, a los que luego me referiré (Lobo del Pozo 2001: 74, 86 y 87).

La existencia de artefactos similares en el área vetona está atestiguada a través de una pareja de elementos de hierro hallada en la tumba 393 de la necrópolis de Las Cogotas (Cardeñosa, Ávila) y de un ejemplar aislado de la 383 (Cabré, 1932: 28, láms. LXXV y LXXVII; Kurtz, 1986-87: 461, fig. 4). En vista de sus analogías con los excavados unos años antes en Atienza, Cabré los sigue considerando camas de bocado, al igual que Kurtz, que establece un grupo tipológico a partir de ellos precisando que "Más que camas en sentido estricto, son topes laterales de bocado" (1986-87: 461). En esta misma zona abulense también se documentan la presencia de ejemplares de bronce, a través de una pieza decorada con troqueles hallada en las inmediaciones de El Raso de Candeleda y publicada por F. Fernández Gómez (1986: fig. 439), quien también la atribuye, a partir de la reconstrucción que hace en el correspondiente dibujo, a una cama lateral de bocado de caballo (Fig. 2.2).

Fuera de estas dos regiones, aparecen elementos aislados en una tumba vaccea de la necrópolis de Las Ruedas, (Padilla de Duero, Valladolid) (Sanz, 1997: $\mathrm{n}^{\circ}$ 1072) realizado en bronce y con decoración troquelada (Fig. 3.2) y también en el área ibérica, donde un único ejemplar, también de bronce, (Fig. 3.3) se incorporó al ajuar de la sepultura 103 de El Cigarralejo (Mula, Murcia) con una cronología del siglo IV (Cuadrado, 1987: 236-238, fig. 91,8).

En relación con estos objetos de brazos curvos hay que poner unos artefactos similares constituidos, como ellos, por un cuerpo central de tendencia prismática y ranura longitudinal y dos apéndices que brotan de las caras más pequeñas y que, en este caso, son rectos. Al igual que aquéllos, también han acabado siendo descritos como camas rectas de bocados, aunque con menos decisión y unanimidad que para los ejemplares de brazos curvos.

Estos objetos rectos, principalmente de bronce, fueron hallados ya en algunas excavaciones del siglo XIX y principios del XX, como las mal conocidas campañas realizadas en la necrópolis de El Acebuchal (Carmona, Sevilla) con anterioridad a las más célebres de Bonsor (Cañal, 1894: 80, fig. 55). Pero también en las que realizara el propio Bonsor (1931: lám. LXIX) en la necrópolis de Carmona (Sevilla). Aunque la trayectoria de estos hallazgos se ha perdido, un objeto muy similar a ambos se conserva en el Museo Arqueológico de Sevilla, probablemente el correspondiente al túmulo G de Acebuchal $^{3}$.

\footnotetext{
2 Se conservan en el Museo Arqueológico Nacional. Parece ser que se mencionan, e incluso se representan, en la inédita aportación de J. Cabré al Catálogo Monumental de España, correspondiente a la provincia de Soria. Debo el dato a A. Lorrio.

3 Museo Arqueológico Provincial de Sevilla ROD 1675. Ingresó en 1945, por depósito municipal, sin procedencia. La extraordinaria coincidencia en formato y dimensiones con el que publica Bonsor como procedente de Carmona (ver fig. 3.4 y 3.5), podría hacer pensar que se trate de la misma pieza. No obstante, los actuales responsables de la Colección de la necrópolis carmonense dudan que un objeto de esta procedencia pueda haber llegado al Museo de Sevilla por vía municipal, por lo que es mucho más probable que se trate de la pieza de Acebuchal, de cuyas antiguas excavaciones se conservan materiales en el Museo hispalense y con la que también guarda gran parecido. Agradezco los comentarios a I. Rodríguez Temiño y a M. Torres.
} 
La presencia de estos objetos de brazos rectos está también documentada en las grandes necrópolis vetonas de la provincia de Ávila, en particular en La Osera, donde aparecen en las tumbas 350 de la zona VI y LX de la zona III, por pares, y fabricados en hierro (Schüle, 1969: lám. 121), (Figs. 3.9 y 4).

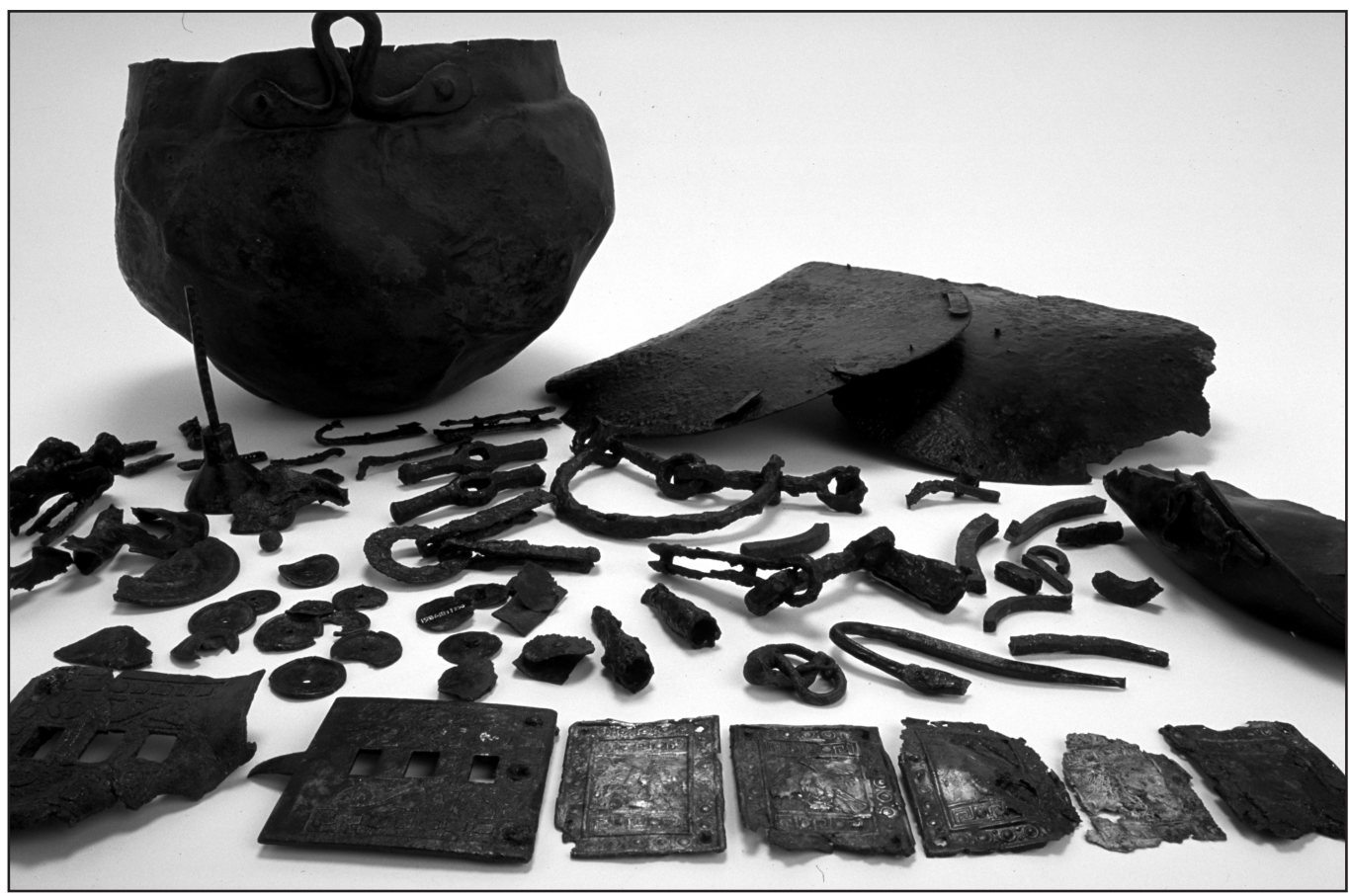

Figura 4. Ajuar de la tumba 350 de la necrópolis de La Osera (Chamartín de la Sierra, Ávila) que contiene un par de objetos de hierro del tipo de brazos rectos hasta ahora inéditos. Foto, José Latova. Museo Arqueológico Nacional (N.C. 3976).

Sin embargo, será ya en la segunda mitad del siglo pasado y en los años iniciales del presente cuando empiece a repararse en ellos con algo más de atención, sobre todo, a partir del tratado de Schüle (1969) y de su aparición en yacimientos orientalizantes y post-orientalizantes del suroeste peninsular, como La Joya (Huelva) o Cancho Roano (Zalamea de la Serena, Badajoz).

En La Joya se hallaron cuatro ejemplares, todos ellos en el interior de la tumba 17, asociados a dos bocados completos y a los elementos de un carro. Sus editores los consideran pasadores (Garrido y Orta, 1978: fig. 49), interpretación que ha sido mantenida y matizada en algunos trabajos posteriores (Jiménez Ávila, 1999: 342-344) y cuestionada en otros, que replantean su uso como posibles camas de bocados (Quesada, 2005: 108).

De Cancho Roano deben proceder dos unidades, aunque hay cierta confusión sobre este extremo. Maluquer publica un ejemplar de bronce en la primera memoria de excavaciones (al que dedica escasa atención en el texto) que relaciona con bocados de caballo (1981: fig. 39); por su parte, $\mathrm{M}$. Blech vuelve a publicar esta pieza reivindicando su condición de bocado pero dudando de su naturaleza broncínea y atribuyéndole unos elementos decorativos que no se observan en el dibujo, lo que da pie a pensar que han aparecido después de una limpieza del objeto (Blech, 2003: 165, fig. 5a). Por otra parte, en el Museo de Badajoz, se conserva una pieza que sí tiene las decoraciones descritas por Blech, y que se refieren a unas esferas y a unas 
incisiones en los extremos de los brazos que parecen reproducir unas semillas de adormidera 4 . Sin embargo, cuando se cotejan el dibujo de Maluquer (el mismo que reproduce Blech) con esta pieza decorada, se comprueba la enorme dificultad — práctica imposibilidad - de aceptar que puedan corresponder a una misma cosa (Fig. 3.6 y 3.7). Habida cuenda de que en el Museo de Badajoz solo se conserva un objeto de estas características, lo más probable es que el primero de ellos, procedente de las iniciales excavaciones de Maluquer, se haya perdido y nunca haya ingresado en esta institución, y que Blech esté describiendo un objeto distinto al que reproduce.

Contribuye a pensar, además, que este dibujo se corresponda con una pieza perdida y no con la $\mathrm{n}^{\mathrm{o}} 10712$ antes de su limpieza, el fuerte parecido que guarda con otro objeto similar conservado en el Museo Nacional de Arqueología de Lisboa incluido dentro de un lote de bronces ecuestres que ha sido dado a conocer solo parcialmente y que se dice proceder del entorno del

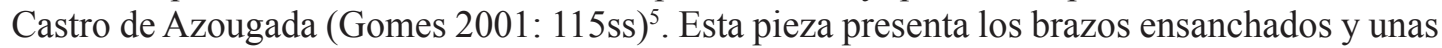
dimensiones muy próximas al ejemplar que publica Maluquer.

El panorama que se obtiene de este repaso no exhaustivo sobre la presencia de este tipo de elementos es el de una gran dispersión cronológica, que abarca prácticamente toda la Protohistoria, desde los ejemplares más antiguos, que pueden situarse a inicios de la Primera Edad

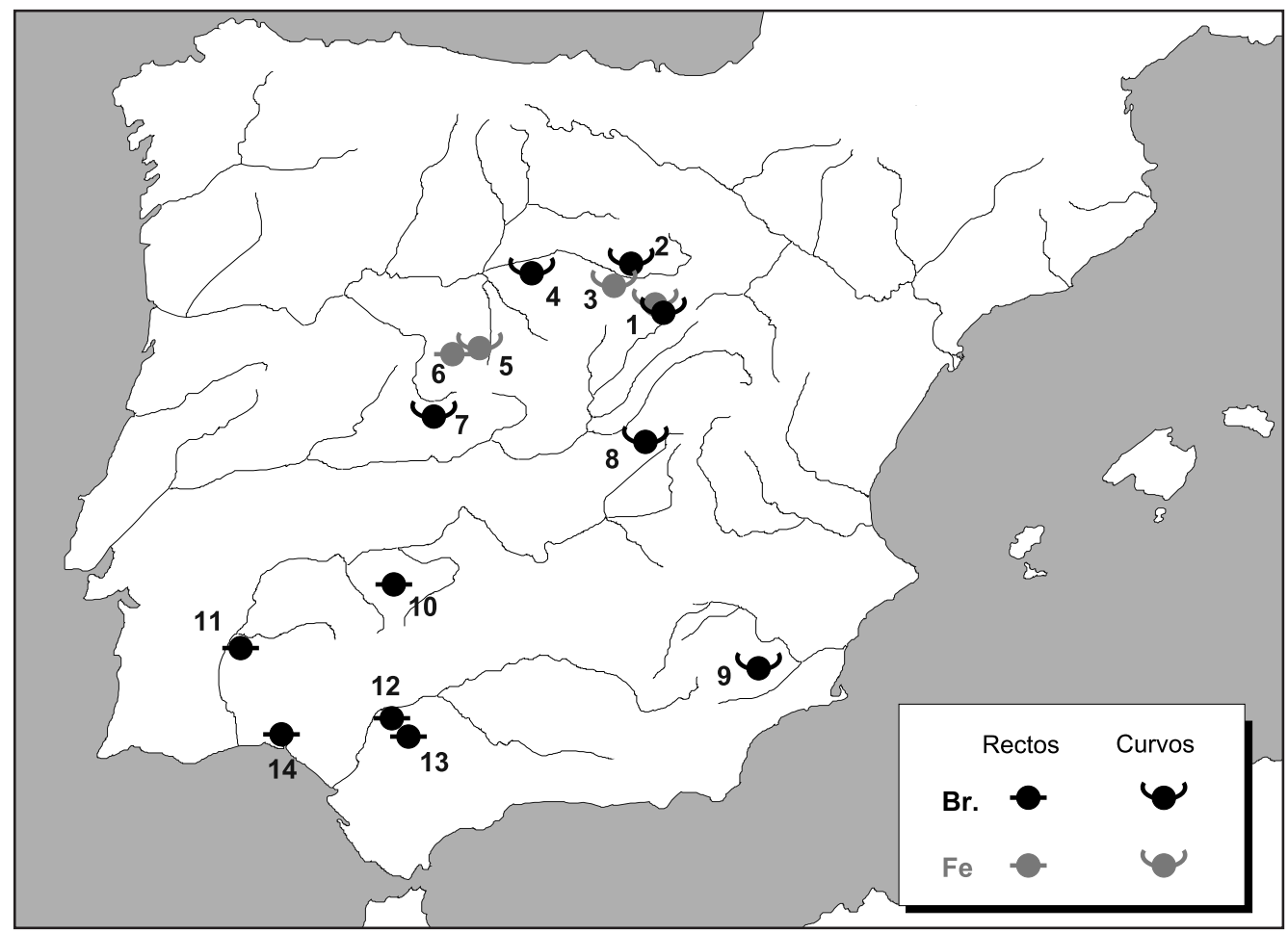

Figura 5. Mapa de distribución de hallazgos peninsulares citados en el texto. Para la numeración, ver tabla 1.

4 Museo Arqueológico Provincial de Badajoz 10712.

5 Museu Nacional de Arqueología 977.83.97. Ha sido, precisamente, el estudio de esta nueva pieza, dentro de un trabajo general sobre este conjunto ecuestre, que estoy preparando conjuntamente con Ana Sofia Antunes, lo que ha suscitado mi interés por este tipo de objetos y la idea de realizar este trabajo de revisión funcional sobre los mismos. 
del Hierro, como evidenciarían los hallazgos de la Tumba 17 de La Joya, que se pueden fechar a finales del siglo VIII, hasta los más recientes, que corresponderían a tumbas del Hierro II, como las meseteñas, que podrían situarse en el siglo IV sino después (Tabla 1).

Desde el punto de vista geográfico la dispersión también es amplia, con presencias desde las costas del suroeste atlántico hasta la provincia de Soria, con una buena representación en el Sistema Central y extensiones hasta el curso del Duero o el Sureste ibérico en forma de hallazgos aislados (Fig. 5).

Desde el punto de vista evolutivo, y aunque no es el objeto de este trabajo un estudio de esas características, parece apreciarse la prioridad cronológica de los ejemplares rectos fabricados en bronce, que se sitúan, sobre todo, en yacimientos orientalizantes y post-orientalzantes del suroeste (Huelva, Acebuchal, Cancho Roano...) incorporándose elementos nuevos, como la introducción del hierro como material de confección o la adopción de los modelos de brazos curvos ya en la Segunda Edad del Hierro, a partir del siglo IV. Estas novedades no desplazan a las antiguas formas, pues se detectan objetos de brazos rectos fabricados en hierro en las tumbas de La Osera y objetos curvos realizados en bronce en La Requijada, El Raso, Las Ruedas y El Cigarralejo, con cronologías de la segunda Edad del Hierro que, en algún caso, pueden situarse con mayor precisión en el siglo IV.

\section{DISCUSIÓN DE LA FUNCIÓN COMO ELEMENTOS DE BOCADOS}

Desde que se planteara la función como bocados para los ejemplares de Atienza, la mayoría de los autores españoles que se han referido a las piezas de brazos curvos han respetado esta inicial atribución. Es el caso, por supuesto, de J. Cabré, que es quien la propone y la mantiene para hallazgos posteriores (1932: 28); de W. Schüle, que reproduce la propuesta y el dibujo de Cabré (1969: lám. 20); de F. Fernández Gómez, que aplica una reconstrucción similar para el ejemplar hallado en las inmediaciones del Raso de Candeleda (1986: fig. 439); de G. Kurtz, que, a partir de ellos, establece un tipo de bocado de camas curvas entre el material ecuestre de Las Cogotas. No obstante Kurtz señala que se trata de topes laterales más que de camas propiamente dichas, si bien no desarrolla la reconstrucción de esta solución (1986-87: 461); de A. Lorrio, que los incluye entre los bocados de camas curvas en su estudio general sobre Los Celtíberos (1997: 235) y que recupera esta adscripción al volver a tratar el ejemplar de Uclés, desvinculándolo así de la inicial propuesta de P. Quintero que no fue más allá de su inicial publicación (2007: 257s). Y es el caso, también, de los autores que han inventariado ejemplares aislados sin realizar un estudio detallado de los mismos, como E. Cuadrado para El Cigarralejo (1987: 238) o C. Sanz para Las Ruedas (1997: 218).

En esta misma línea, pero con algunos reparos, se sitúa el estudio de la necrópolis de Carratiermes, donde aparecen dos ejemplares "desparejados" —expresión que ya de por sí presupone que tendrían que formar pareja - en sendas tumbas de este cementerio soriano. Los ejemplares termestinos se agrupan en un subgrupo específico (bridón de topes curvos) dentro de los bocados de camas curvas (Tipo 4). Serían los topes de los frenos e irían destinados a proteger el labio del animal (Lobo del Pozo, 2000: 74). La autora, no obstante, señala un número de acertadas dificultades a la hora de considerar como bocados estas piezas, como la ausencia de perforaciones de sujeción a la brida o la extraña disposición que adoptarían con respecto a la cabeza del animal, a pesar de todo lo cual nunca considera otra opción que la de que se trate de piezas de bocado (Ibidem: 74, 86 y 87).

Para las piezas de brazos rectos el proceso de identificación no ha sido tan uniforme, verificándose una cierta tradición que los vincula, aunque de forma dispar y discontinua, con 
sistemas de abotonadura. Así, si el ejemplar de Acebuchal se identificó como una improbable pieza de cinturón (Cañal, 1894: 78ss), los cuatro gemelos de La Joya se han interpretado como pasadores que se suponen relacionados con el sistema de tracción del carro (Garrido y Orta 1978: 84, fig. 49) o como piezas de hebilla de la zona de la cabezada (Jiménez Ávila, 1999: 342). Pero la identificación del ejemplar de Cancho Roano como bocado (Maluquer, 1981: fig. 39) ha basculado la interpretación hacia este ámbito, y en este sentido se han posicionado, ya más recientemente, M. Blech en su estudio del material de este mismo yacimiento (2003: 165) o F. Quesada en trabajos más generales donde considera, incluso, que los ejemplares de La Joya puedan ser bocados (2005: 118).

La interpretación como bocados de los ejemplares de Atienza debe partir de su similitud formal con las camas de frenos con los que conviven en las dos tumbas en que fueron hallados (constituidas por placas de perfil curvo o liriformes), más que de un proceso de reflexión tipológica o tecnológica sobre los mismos. Probablemente, de no haberse dado esta feliz coincidencia, su definición funcional habría sido más dudosa y es que, como ya he avanzado, existen poderosas razones de tipo morfológico, técnico y contextual que impiden tal consideración.

Entre las primeras están las propias dimensiones de la ranura que perfora estos utensilios por su parte central. El ancho de las camas de la sepultura 16 de Atienza es de $1 \mathrm{~cm}$, con lo que la apertura de la ranura es de tan solo unos milímetros, al igual que la de El Raso (Fig. 2). Las de La Joya son de entre 2 y $3 \mathrm{~mm}$ de anchura (Fig. 3.8). En este espacio es absolutamente imposible que pueda instalarse el cordón de un filete al uso, como se desliga fácilmente cuando se observan los dibujos reconstructivos de Cabré (reproducido, empero hasta la saciedad) o el de F. Fernández Gómez, donde los cordones de los bocados son sustancialmente más gruesos (Fig. 2). Ni siquiera en el caso de que, como en alguna ocasión se ha propuesto, el filete estuviera confeccionado en alguna sustancia perecedera, como el cuero, tendría éste dimensiones suficientes para asegurar su resistencia ni el espacio mínimo requerido para evolucionar libremente en el interior de estas estrechas perforaciones.

Es cierto que algunos de estos objetos, como los de Cancho Roano o La Osera, presentan ranuras algo más amplias. Pero, como norma general para el estudio de la cultura material, si algunos miembros de un grupo tipológico no cumplen los requisitos básicos que determinan una funcionalidad concreta, debemos descartar dicha funcionalidad para todo el grupo.

Otro de los atributos que diferencian estos elementos - en particular los de brazos curvos- de las verdaderas camas de bocado es la disposición de la perforación, que normalmente es transversal al plano que forma la placa mientras que en este caso es coincidente con el mismo. Esto - y aquí entramos en los razonamientos de tipo técnico- obligaría a que los supuestos bocados se proyectaran en horizontal hacia el exterior de la cabezada, generando unas extrañas excrecencias a modo de cuernos que, en el mejor de los casos, entorpecería el juego de las riendas y, en el peor, podrían resultar peligrosas para quien manipulara al caballo desde el suelo en caso de que el animal pudiera hacer un extraño con la testa embridada.

Otro razonamiento técnico, que ya ha sido apuntado (Lobo del Pozo, 2001: 74) es la total ausencia de vestigios de agarre en estos objetos, y esto es algo que es de aplicación tanto a los ejemplares curvos como a los rectos: ni orificios para sujeciones, ni anillas adheridas, ni vestigio alguno de que los tuvieran se han conservado en ninguna de las unidades recogidas. Y estos elementos son absolutamente necesarios para unir la cama a las correas de la brida y así ejercer su verdadera función de sujetar el filete, que es la que corresponde a un objeto de este cometido.

Por tanto, existen elementos técnicos y tipológicos que apuntan decididamente en contra de la consideración como camas o como topes de bocados de estos artefactos. 
Desde el punto de vista contextual, lo primero que hay que señalar es que ninguna de estas supuestas camas ha aparecido nunca con sus correspondientes filetes ni con otros elementos de cabezada que a ellas se les puedan asociar de manera directa. O lo que viene a ser lo mismo: ninguno de los bocados hispánicos de la Edad del Hierro (que se cuentan ya por centenares) que haya llegado hasta nosotros con un cierto grado de integridad, presenta semejantes aditamentos.

Los primeros ejemplares que se interpretaron en esta línea aparecieron siempre formando parejas (Atienza, La Requijada...) lo que, sin duda, favoreció su percepción como camas de bocados. Sin embargo, el número de hallazgos individuales en contextos cerrados resulta ya bastante significativo: dos en Carratiermes, uno en Cogotas, otro en El Cigarralejo, uno muy probable en El Acebuchal, otro más que podíamos considerar dentro de los mismos parámetros en el conjunto del Museo de Lisboa, y probablemente también los de Cancho Roano, que unen su individualidad a su convivencia con juegos de camas y bocados en los que tienen difícil cabida como tales. Es decir, la mitad de los contextos conocidos (Tabla 1).

En relación con los contextos también hay que decir que es casi una constante la convivencia de estos objetos con bocados o con elementos de cabezada, siendo muy pocos los conjuntos bien documentados donde no se produce esta asociación. Pero esto, lejos de ser un argumento

\begin{tabular}{|c|c|c|c|c|c|c|}
\hline & Yacimiento & Conjunto & Núm & Tipo & Mat. & Bibliografía \\
\hline \multirow{2}{*}{1} & \multirow{2}{*}{ Atienza (GU) } & $\mathrm{T}-15$ & 2 & Curvo & $\mathrm{Br}+\mathrm{Fe}$ & Cabré, 1930, Lám. XVI \\
\hline & & $\mathrm{T}-16$ & 2 & Curvo & $\mathrm{Fe}$ & Cabré, 1930, Lám. XVII \\
\hline 2 & La Requijada (SO) & $?$ & 2 & Curvo & Bronce & Cabré, 1930, p. 23 \\
\hline \multirow{2}{*}{3} & \multirow{2}{*}{ Carratiermes (SO) } & $\mathrm{T}-3$ & 1 & Curvo & $\mathrm{Fe}$ & Argente et al., 2001, p. 86 \\
\hline & & T-9 & 1 & Curvo & $\mathrm{Fe}$ & Argente et al., 2001, p. 86 \\
\hline 4 & Las Ruedas (VA) & secund. & 1 & Curvo & Bronce & Sanz, 1997, nº 1072 \\
\hline \multirow{2}{*}{5} & \multirow{2}{*}{ Cogotas (AV) } & $\mathrm{T}-383$ & 1 & Curvo & $\mathrm{Fe}$ & Cabré, 1932, Lám. LXXV \\
\hline & & $\mathrm{T}-393$ & 2 & Curvo & $\mathrm{Fe}$ & Cabré, 1932, Lám. LXXVII \\
\hline \multirow{2}{*}{6} & \multirow{2}{*}{ La Osera (AV) } & T-III-LX & 2 & Recto & $\mathrm{Fe}$ & Schüle, 1969, Lám. 121 \\
\hline & & $\mathrm{T}-350$ & 2 & Recto & $\mathrm{Fe}$ & Inéditos (MAN 1986/81/VI/350) \\
\hline 7 & El Raso (AV) & Superf. & 1 & Curvo & Bronce & Fdez. Gómez, 1986, fig. 439 \\
\hline 8 & Uclés (CU) & $?$ & 1 & Curvo & Bronce & Lorrio 2007, fig. 2.7 \\
\hline 9 & El Cigarralejo (MU) & $\mathrm{T}-103$ & 1 & Curvo & Bronce & Cuadrado, 1987, fig. 91.8 \\
\hline \multirow{2}{*}{10} & \multirow{2}{*}{ Cancho Roano (BA) } & - & 1 & Recto & Bronce & Maluquer, 1981, fig. 39 \\
\hline & & - & 1 & Recto & Bronce & Inédito (MAPBA 10712) \\
\hline 11 & Zona de Moura (PORT) & - & 1 & Recto & Bronce & Inédito (MNA 977.83.97) \\
\hline 12 & Necr. Carmona (SE) & - & 1 & Recto & Bronce & Bonsor, 1931, Lám. LXIX \\
\hline 13 & El Acebuchal (SE) & - & 1 & Recto & Bronce & Cañal, 1994, fig. 55 \\
\hline 14 & La Joya (HU) & $\mathrm{T}-17$ & 4 & Recto & Bronce & Garrido y Orta, 1978, fig. 49 \\
\hline
\end{tabular}

Tabla 1. Cuadro sinóptico con la ordenación de los hallazgos recogidos en el texto. 
a favor, se convierte en una razón en contra cuando comprobamos que lo habitual es que en las tumbas del Hierro peninsular se deposite una única brida y que, cuando se disponen dos (fenómeno minoritario, normalmente asociado a enterramientos de carros o de yugos), suelen ser del mismo tipo. Por tanto, la presencia de estos objetos junto a equipos ecuestres que ya tienen su cabezada completa, en la mayor parte de los casos dotada de completos juegos de frenos, resulta arduamente interpretable como evidencia de un segundo (y siempre incompleto) juego de bocados.

\section{PARALELOS EUROPEOS Y FUNCIONALIDAD}

Resulta importante (y a la vez curioso) valorar el papel que haya podido tener el tratado de W. Schüle (1969) en la difusión y generalización de la interpretación de este tipo de artefactos como camas de bocados ecuestres, al haberse convertido en una fundamental obra de referencia para el estudio de las culturas de la Edad del Hierro de la Península Ibérica durante muchos años, y al haber reproducido (y ampliado) el dibujo de Cabré que reconstruye como camas los elementos de la tumba 16 de Atienza en su lámina 20 (Fig. 2.1). En esta obra se recoge también el ejemplar procedente de la necrópolis de Carmona y se lo relaciona con un tipo de útiles bien conocido en las culturas del Centro de Europa, de los que se presenta un mapa de distribución con las unidades editadas hasta la fecha (Ibidem: mapa 10). Sin embargo, la excepcionalidad de este viejo hallazgo (el de Acebuchal no se incluye en esta obra) hace que se le dedique poca atención, al punto de que otros elementos análogos, como la pareja de la de la tumba III-LXIX de La Osera, que reproduce en su lámina 121, no se consideran dentro de la misma categoría. En cualquier caso hay que atribuir a Schüle el mérito de haber relacionado por primera y única vez en la literatura arqueológica hispana, alguno de estos objetos con sus congéneres europeos ${ }^{6}$.

Efectivamente, en las culturas europeas de Hallstatt y La Tène existe un abundante repertorio de objetos que guardan un estrechísimo parecido con los que aquí estamos examinando, en particular con los de brazos rectos y que, como ellos, aparecen en contextos relacionados con atalajes ecuestres y, más propiamente, con enterramientos de carros. Comprenden, por tanto, una barra cilíndrica o prismática con un ensanchamiento central que aloja una perforación o ranura que puede afectar diversas formas. Al igual que los ejemplares peninsulares se fabrican tanto en bronce como en hierro y, dentro de este formato general, revisten una cierta variedad tipológica (Trachsel, 2004: 263). Existen modelos que son especialmente próximos a algún ejemplar del repertorio hispano, como los que conforman un cajetín prismático en la zona central y se dotan de esferas decorativas en los extremos, desarrollando un modelo muy parecido al del ejemplar de Cancho Roano que aquí se presenta (Fig. 6).

El repertorio más completo de estos objetos es el que realiza, M. Trachsel (2004: $463 \mathrm{ss),}$ que completa sustancialmente el anterior de Kossack (1954) y que eleva a más de 50 los ejemplares ya conocidos, casi todos procedentes de tumbas de carro, repartidas sobre todo por las regiones de Bohemia y Baviera, pero con algunas incursiones en Austria, Hungría, Polonia, la península balcánica y los Países Bajos.

Aunque la mayoría de las unidades conocidas adoptan la tipología de brazos rectos, existen algunos hallazgos que podrían relacionarse con los objetos de brazos curvos, como algún

\footnotetext{
6 Ver también Jiménez Ávila, 1999: 342, aunque esta parte del tratado original no aparece en la publicación definitiva.
} 


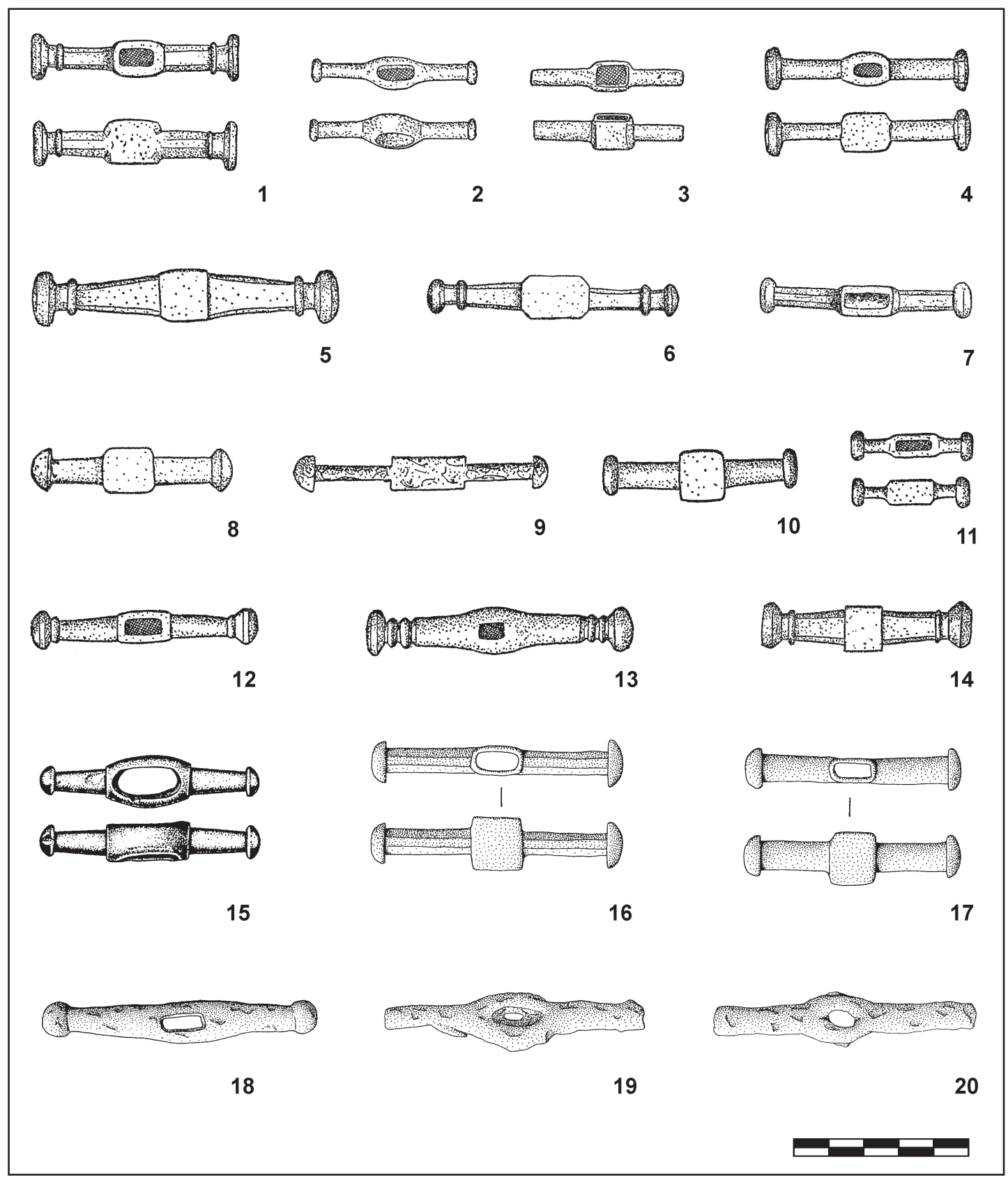

Figura 6. Objetos de bronce (1-17) y hierro (18-20) de brazos rectos procedentes de diversos yacimientos centroeuropeos del Hallstatt-C, s. Kossack, 1954 (1-14); Trachsel, 2004 (15) y Pare, 1992 (16-20).

conjunto de elementos decorados con terminaciones zoomorfas procedentes de la región de Baviera (Fig. 7) que han sido asimilados a las mismas funciones (Hoppe, 1986: 61).

A estos ejemplares hallstáticos habría que añadir los de la época de La Tène, peor sistematizados, y que son especialmente frecuentes en las islas británicas, donde alcanzan la época romana, como evidencian los ejemplares hallados en el célebre depósito de Polden Hill (Somerset), en el que aparecen conviviendo con otros elementos ecuestres (Brailsford, 1975: 


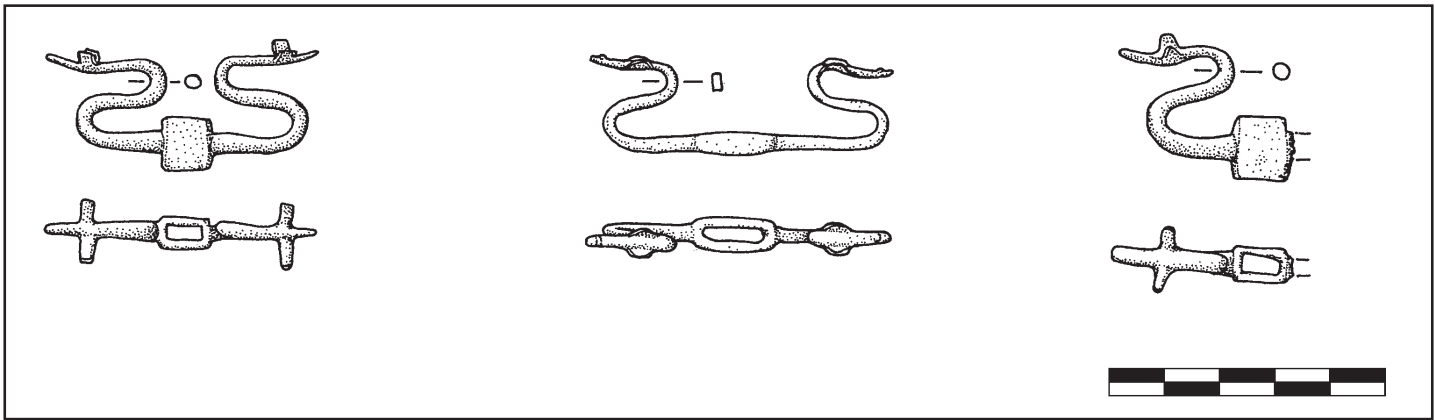

Figura 7. Elementos zoomorfos de la tumba de Thälmassing (Baviera), s. Hoppe, 1986.

230, fig. 6). A pesar de su más reciente cronología, los ejemplares latenienses, caracterizados por sus brazos ensanchados, son especialmente próximos a algunos de los más antiguos exponentes peninsulares, sobre todo los de la tumba 17 de La Joya, pero también en menor medida al ejemplar perdido de Cancho Roano y al del Museo de Lisboa (Fig. 8). Algunos de estos utensilios portan las decoraciones típicas de la artesanía céltica de este momento, trabajadas mediante incisión o a base de incrustaciones de coral y esmaltes de colores, generando productos muy vistosos.

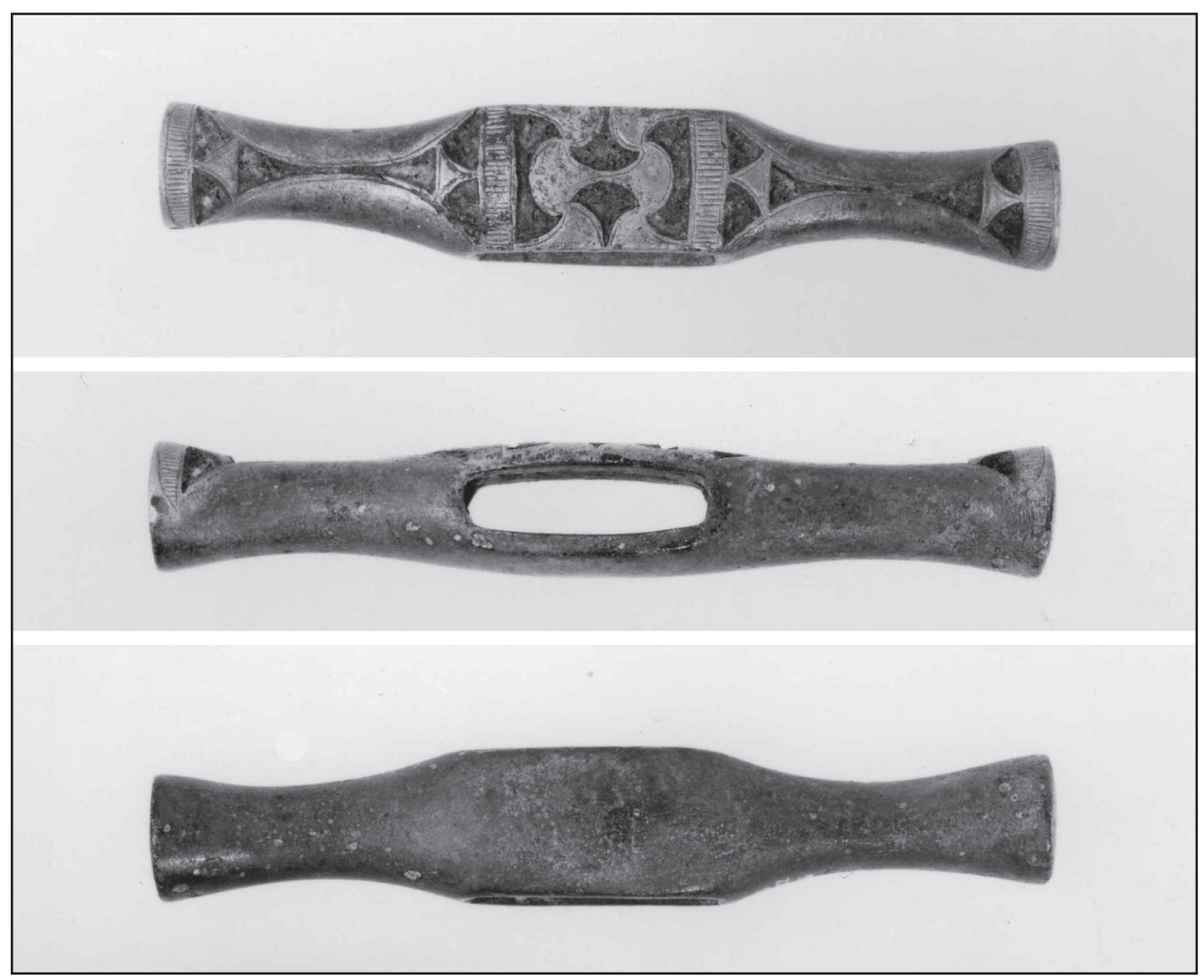

Figura 8. Pasador de bronce hallado en el depósito de Polden Hill (Reino Unido). Obsérvese la decoración unifacial. Fotos British Museum. 
Las denominaciones de que son objeto estos utensilios en sus zonas de expansión más habituales (knebel, en alemán; toggle en inglés) ${ }^{7}$ los alejan claramente del terreno de las piezas de bocado para aproximarlos al de los sistemas de cierres o abotonaduras de correajes, a los que han sido adscritos genéricamente desde que se realizaran los primeros hallazgos. Este reconocimiento genérico está más en la línea de su uso como pasadores o hebillas que en el caso español ha sido minoritariamente propuesto para los ejemplares de La Joya o Acebuchal, como ya he señalado.

Pero más allá de esta clasificación, algo difusa, con que han venido siendo reconocidos tradicionalmente, interesa destacar algunas reconstrucciones más recientes realizadas a partir de varias excavaciones de sepulturas del centro de Europa, donde al hallazgo de los depósitos prácticamente in situ, se unen unas extraordinarias condiciones de conservación que permiten, en algunos casos, la recuperación de materiales como las correas o las bandas de cuero. En este sentido, destacan los trabajos de J.K. Koch sobre las tumbas de Hochdorf y ThalmässingAlfershausen (Koch, 1999; 2004; 2006) seguidos luego para otros conjuntos con similares componentes, como el de Oss, en los Países Bajos (Van der Vaart- Verschoof, 2011).

En estos enterramientos, objetos de bronce asimilables a los hallazgos hispánicos, se encuentran asociados a anillas metálicas que, cuando las condiciones de conservación y documentación permiten verificarlo, se sitúan en la zona de unión del yugo con las tiras de piel que uncirían a los caballos. De hecho, lo más

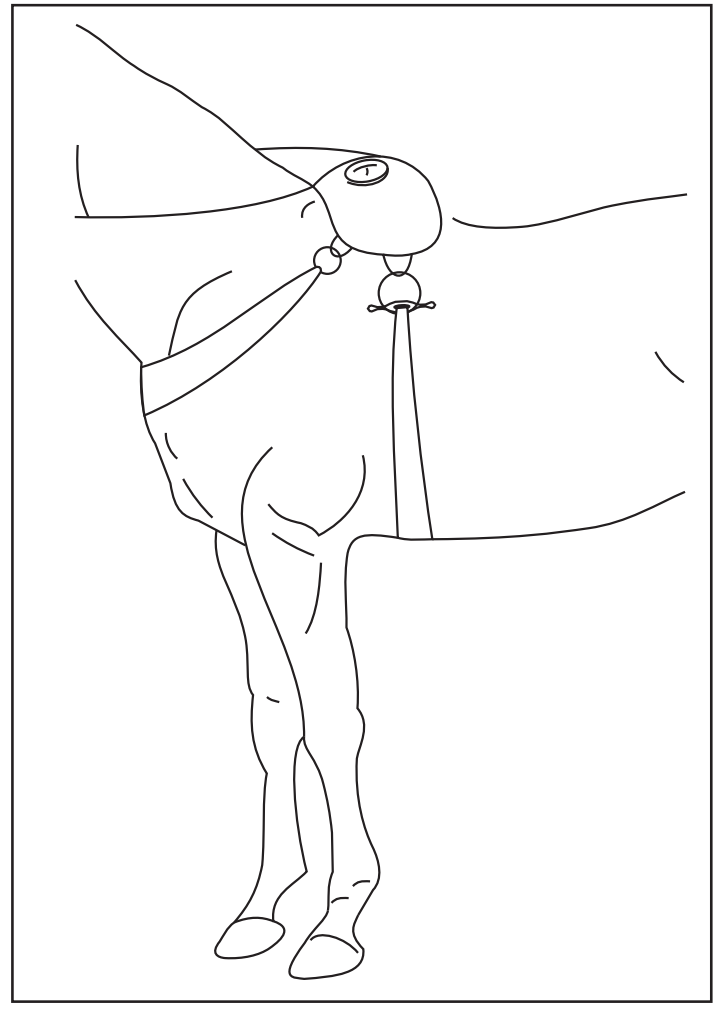

Figura 9. Sistema de cierre del yugo de Oss (Países Bajos) según propuesta de S. Van der Vaart-Verschoof (2011). frecuente es, que estos knebel aparezcan por parejas, coincidiendo con el número de caballos que tirarían de sus correspondientes carros funerarios y con el número de bocados (también completos) que en estas sepulturas suelen hallarse (Pare, 1992). Esta disposición propicia la reconstrucción de estos elementos como componentes del cierre de los correajes del sistema de tracción, que irían unidos a una cinta de cuero, cuyo extremo se agarraría a la perforación central, mientras que las anillas irían sujetas a los extremos del yugo. El cierre se aseguraría por el procedimiento de pasar las piezas alargadas y sujetas a las correas por el interior de la anilla, donde quedarían aprisionadas al contar con una longitud superior al diámetro de éstas (Fig. 9).

Esta función de cierres, a través de este simple procedimiento, es la que, a la luz de la argumentación que he expuesto aquí, debe atribuirse a los objetos hispánicos que estamos examinando, si bien de deben aplicar a éstos una serie de particularidades y matices en función de las características específicas del material peninsular. Sobre estos problemas trataré en el siguiente apartado.

\footnotetext{
7 Términos que podrían traducirse por agarrador o mordaza y por botón alargado, respectivamente.
} 


\section{ALAMARES METÁLICOS: UN NUEVO TIPO DE ELEMENTO DE ATALAJE ECUESTRE EN LA PROTOHISTORIA PENINSULAR}

La individualización de un tipo artefactos con una función específica, dentro del conjunto de objetos metálicos que conforman el utillaje ecuestre característico de la Edad del Hierro peninsular, exige abordar una serie de cuestiones fundamentales, tales como su descripción, su definición y la problemática que suscitan las peculiaridades de estos hallazgos peninsulares en relación con los europeos. En este último apartado hay que señalar cuestiones que atienden a su dimorfismo, a su relación con elementos de carro o a su cantidad en las sepulturas, sin olvidar las que atañen a la cronología y a las relaciones culturales que se derivan de su evidente similitud con el material hallstático y lateniense.

Desde el punto de vista morfológico se trata de piezas realizadas a partir de una barra maciza, ensanchada en su parte central, donde aparece atravesada por una ranura longitudinal. De esta zona medial brotan dos brazos simétricos, transversales a la dirección de la ranura, que pueden afectar forma recta o curva. Se fabrican indistintamente en bronce y hierro y, a partir de este esquema básico, pueden adoptar formas muy diferentes. A veces aparecen decorados.

Su función es la de servir de cierre a los correajes que forman parte de los arneses ecuestres mediante el paso de una cinta de cuero por la ranura que todos tienen en su parte central que después se cosería sobre sí misma, formando así un travesaño fijo (Figs. 10.1 y 10.2).

El cierre se realizaría pasando este travesaño o pasador por el interior de una argolla sujeta a otro elemento, asegurando de este modo la fijación de ambos. En el caso de los modelos europeos se ha propuesto que el engarce pase por una anilla metálica, pues es frecuente que en las tumbas hallstáticas aparezcan asociados a argollas de este tipo ${ }^{8}$. Sin embargo, esto no suele suceder así en los contextos hispánicos, por lo que es posible que las presillas metálicas se prendieran en ojales o en lazos trabajados directamente en el cuero a modo de cinta o cordón (Fig. 10.3).

Para definir esta clase de cierre sirven las denominaciones genéricas que se han venido utilizando en los diferentes idiomas que las han reconocido: botones, pasadores, presillas... Sin embargo, existe en castellano un término específico para este tipo de engarce que, por esta razón, propongo aquí para su aplicación a estos artefactos: el concepto, de etimología hispanoárabe, de 'alamar'. El término, en su origen ('alam - قُمال ع) designa un adorno formado a partir de un lazo o un cordón que se cose sobre un tejido, y con este sentido se aplica, sobre todo, a los sistemas de cierre de algunas indumentarias militares modernas, como las casacas y dolmanes de los uniformes napoleónicos que, partiendo del botón propiamente dicho, se complementan con una serie de complicadas lacerías de carácter ornamental. Pero, a partir de ahí, se usa más comúnmente para designar a este tipo de abotonadura en sus versiones más sencillas, constituidas por un simple lazo u ojal atravesado por un botón transversal (como en las otrora populares trencas) o, simplemente, para designar a dicho botón ${ }^{9}$.

Las peculiaridades que adquiere el material peninsular en relación con el europeo merecen una pequeña discusión, pues a la extrema similitud formal de algunos de sus componentes y a la coincidencia del tipo de contextos en algunos casos, se oponen otros parámetros donde estas similitudes no son tan evidentes.

\footnotetext{
8 Aunque también se ha señalado que esto no tiene por qué ser siempre así (ver Koch, 2004). De hecho, a partir de esta reconstrucción algunos autores han llamado la atención sobre la ausencia de huellas del rozamiento que habrían provocado estas anillas metálicas en los pasadores (Brattinga, 2012: 31).

9 La definición de la RAE es: Presilla y botón, u ojal sobrepuesto, que se cose, por lo común, a la orilla del vestido o capa, y sirve para abotonarse, o meramente para gala y adorno o para ambos fines.
} 


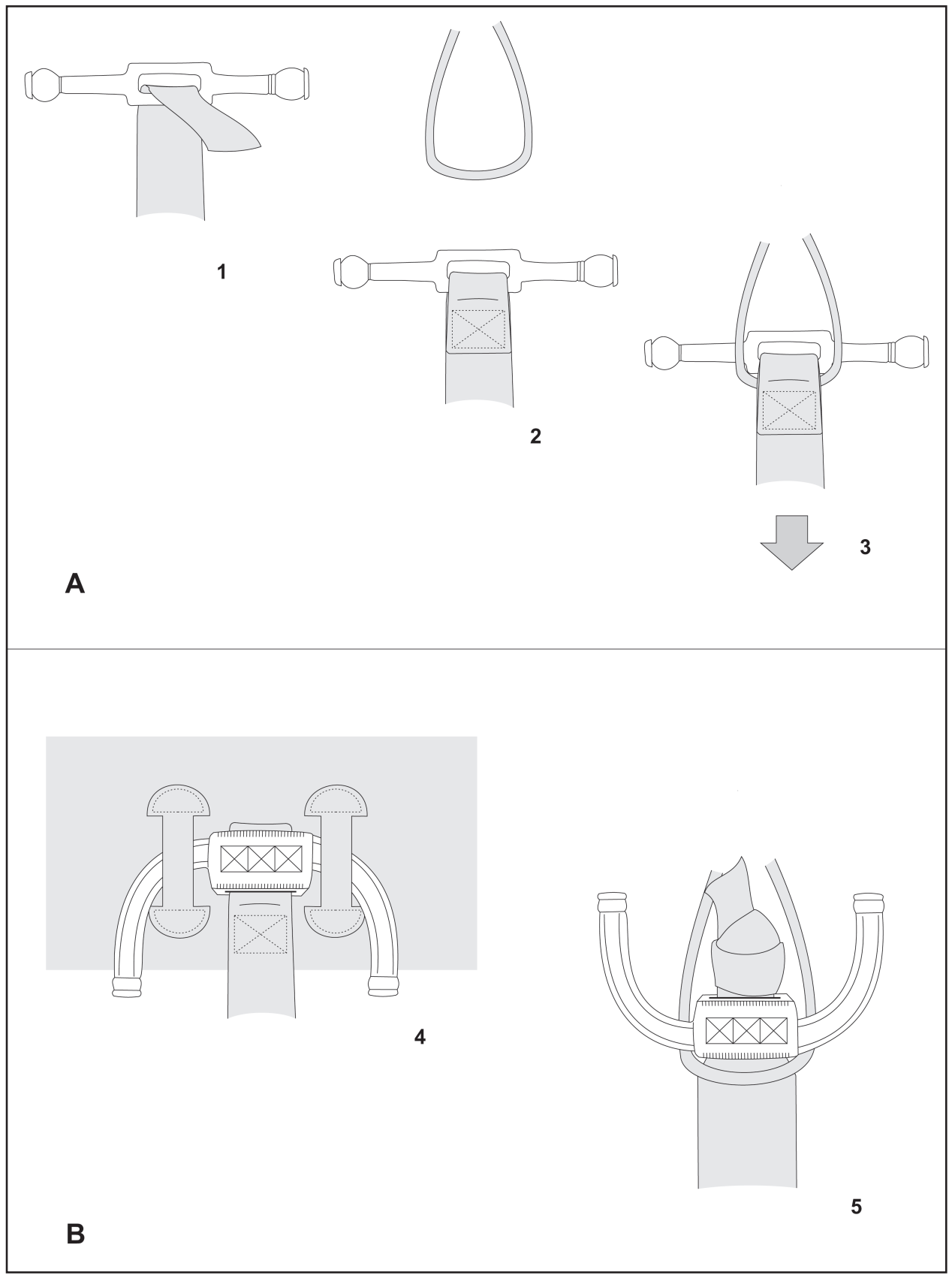

Figura 10. Propuesta de reconstrucción del funcionamiento de los alamares protohistóricos de la Península Ibérica. A. Procedimiento de sujeción y uso para alamares rectos. B. Distintas propuestas de uso de un alamar de brazos curvos.

Es el caso, por ejemplo, del dimorfismo que presentan los ejemplares españoles, que se aparta de la uniformidad de los europeos, casi siempre rectos, y que obliga a diferenciar dos tipos fundamentales entre el material peninsular de acuerdo al formato recto o curvo de sus apéndices. De hecho, si entre el material hispánico no se hubiera dado esta peculiaridad, es posible que nunca se hubieran confundido con camas de bocados. Si esta diferencia está moti- 
vada por factores funcionales o es simplemente una moda estética es algo difícil de determinar. Desde el punto de vista funcional un alamar de brazos curvos puede ejercer un ajuste mayor que uno recto si se disponen los apéndices hacia abajo, pero también corre el riesgo de girarse sobre sí mismo con más facilidad si las costuras no están bien ajustadas. La posibilidad de que para este tipo de cierres se usaran dobles ojales (al modo de lo que sucede con los llamados pasadores ancoriformes) está abierta, tal y como se sugiere en la figura 10.4. Pero es igualmente posible que se aplicaran en posición inversa, con los brazos hacia arriba, atendiendo al formato de los ejemplares europeos que se han mencionado y cuyas decoraciones apuntan a esta disposición (Fig. 10.5).

En relación con el uso de los alamares curvos y de sus peculiaridades hay que señalar también el tema de la decoración que portan algunos de ellos y que, en los casos conocidos de El Raso, Uclés y Las Ruedas (probablemente también en la tumba 16 de Atienza), se sitúa por las dos caras mayores. La presencia de decoración por ambas caras es poco compatible con el sistema de cosido al arnés que aquí propongo, que ocultaría una de las caras decoradas. Las posibles explicaciones son, o que el artesano broncista realice la decoración a troquel por las dos caras (un mecanismo fácil) sabiendo que una de ellas va a quedar oculta y dándola por perdida (Fig. 10.4), o que el sistema de sujeción de estas piezas decoradas a la correa fuera distinto al de la costura y dejara las dos caras al descubierto (ver, por ejemplo, la fig. 10.5 donde se propone un simple nudo final, aunque las soluciones pueden ser múltiples). Conocidas algunas prácticas decorativas de la cultura celtibérica, que privilegian un solo lado de los artefactos (cfr. Lorrio y Sánchez de Prado 2009: passim; también Almagro-Gorbea y Torres 1999, donde se tratan algunos de estos utensilios), la primera opción parece menos probable, y a este respecto, hemos señalado también cómo para los alamares latenienses, decorados con técnicas de mayor complejidad, se diferencia un anverso decorado de un reverso liso (Fig. 8), lo que puede estar sugiriendo procedimientos diferentes.

Una segunda cuestión de debate atañe a la relación de estos mecanismos de cierre con los yugos y, por lo tanto, con los carros, algo que constituye una constante en los hallazgos europeos, pero que no parece reproducirse en todos los casos peninsulares. La relación alamaresyugos aparece claramente documentada en el caso de la tumba 17 de La Joya, donde se halló el carro completo, y es lo más probable que se diera en el conjunto del Museo de Lisboa y en Cancho Roano, donde aparecen pasarriendas y otros elementos que evidencian la presencia de sistemas de tracción (Gomes, 2001; Blech, 2003). De forma menos clara, también podría reconocerse en Acebuchal, de donde procede un pasador sagital similar a los que se hallaron con el carro de La Joya (Cañal 1894: fig. 58; cfr. Garrido y Orta, 1978: fig. 48). Pero en el resto de los hallazgos, que significativamente se apartan del suroeste orientalizante, no hay el más mínimo vestigio de yugos.

Las opciones que se abren para explicar este comportamiento diferencial son de varios tipos: o bien existen deposiciones de yugos sin más elementos hasta ahora reconocidos que los alamares en las tumbas vetonas y celtibéricas donde estos objetos aparecen (algo que parece poco probable) o bien, este sistema de cierre se usó para ajustar otro tipo de componentes en arneses de caballos no uncidos, como gualdrapas, pretales, etc. Ello sin olvidar que el contenido del ajuar de una tumba no siempre obedece a una lógica funcional y que puede estar determinado por factores simbólicos, post-deposicionales, etc. (ver, por ejemplo, para el caso de los yugos peninsulares, depuestos sin el resto del carro, Jiménez Ávila y Muñoz, 1997).

En este sentido, pueden llamar la atención algunos depósitos, como el de la tumba 103 de El Cigarralejo, donde el alamar, de brazos curvos, se incorpora al ajuar de un guerrero ibérico completamente desprovisto de cualquier otro elemento de jaez (Cuadrado, 1978: 236ss). Este dato podría cuestionar el uso exclusivamente ecuestre, que aquí propongo, para este sistema 
de cierre. Pero también es cierto que existen inclusiones aisladas de otras piezas bien reconocidas como arreos en tumbas prerromanas, lo que obligaría a un similar cuestionamiento. Al respecto, puede citarse, sin salir del repertorio de yacimientos de este trabajo, un agarrador ancoriforme hallado aisladamente en la tumba 2 de la necrópolis vaccea de Las Ruedas (Sanz, 1997: 53).

Ligada con este tema, está también la cuestión del número de alamares por conjunto ecuestre. Ya he señalado cómo en las tumbas de Hallstatt y en los depósitos bien conocidos de La Tène, suele darse una ratio de un alamar por caballo, algo que se deduce tanto de la conformación del carro (cuando éste existe) cuanto de la cantidad de bocados, en caso de que no haya vehículo (Kossack, 1954; Pare, 1992). Esta combinación sugiere que las correas de sujeción estarían fijas a uno de los lados de las gamellas del yugo y sueltas por el otro extremo, que es por donde se cerrarían con el alamar o con otros sistemas de trabazón, como se ha documentado en algunos vehículos bien conservados como el de Hochdorf (Koch, 1999; 2006).

Sin embargo, en la Península Ibérica raramente se produce este binomio. En la tumba 17 de La Joya, el conjunto cerrado mejor conservado, se hallaron cuatro alamares en un carro de dos caballos, lo que sugiere que las bandas del yugo estarían sueltas por ambos lados, como parece darse excepcionalmente en algunos sistemas de tracción europeos, donde aparecen yugos con cuatro anillas (Piggott, 1983: fig. 138). Pero tampoco es descartable que, como hemos señalado para el caso de los alamares del área céltica, éstos se usaran para unir simultáneamente componentes distintos al yugo. En el caso del conjunto del Museo de Lisboa hay un alamar por caballo, mientras que en Cancho Roano hay menos de uno, tratándose éste de un yacimiento donde los conjuntos funcionales están de por sí bastante incompletos. También en el área céltica se multiplican las posibilidades, con parejas que acompañan a un solo bocado o elementos individuales, que sugieren soluciones diversas, como mantas cogidas con dos alamares (uno a cada lado), con uno solo, o uso de dos piezas para unir simultáneamente elementos diversos (gualdrapa y pretal, por ejemplo).

Lo que sí parece constatarse, y este es un tema que aquí solo pretendo señalar brevemente, es un comportamiento diferencial entre los hallazgos del suroeste que, por lo general, presentan una cronología más antigua y tipológicamente son todos de brazos rectos, con los de las zonas centrales de la península, en conjunto más recientes y con un predominio - aunque no absoluto - de la modalidad de brazos curvados, que dan cabida ya a ejemplares fabricados en hierro. Este dualismo coincide además, a grandes rasgos, con la asociación o no de estos elementos a vehículos, algo que creo más atribuible a los cambios ideológicos que se producen en las poblaciones peninsulares entre la Primera y la Segunda Edad del Hierro que a una diversa funcionalidad entre los dos tipos reconocidos.

Pero, sin duda, los problemas más interesantes que suscitan estos utensilios tan característicos de la Protohistoria centroeuropea, se refieren a las inferencias culturales e históricas que se derivan de su presencia en la Península Ibérica, sobre todo, cuando ésta puede rastrearse desde un momento tan temprano como el que representan las tumbas de La Joya, plagadas de elementos de conexión con el mundo mediterráneo y oriental donde no se registra este tipo de mecanismos. Y lo mismo cabría decir para otros hallazgos suroccidentales como los de Acebuchal, el Museo de Lisboa o Cancho Roano. En este sentido y, aunque sea a modo de esbozo, cabe señalar la presencia de otros elementos del utillaje ecuestre peninsular que parecen apuntar hacia el mismo tipo de vínculos. Así, por ejemplo, los ya citados pasadores sagitales hallados en Acebuchal y en la tumba 17 de La Joya asociados al carro, que guardan un estrecho parecido con los llamados Messerförmige Anhänger ${ }^{10}$, que aparecen relacionados

10 Que se puede traducir como "colgantes en forma de cuchillo". 
con los sistemas de abrochadura de correajes de algunos vehículos hallstáticos (Koch, 1999: 180-181); la cruz tubular de Azougada (Schüle, 1969: lám. 111; Trachsel, 2004) y, quizá también, grupos de cadenas radiales como el de Cancho Roano (Maluquer, 1983: fig. 20), que se podrían relacionar con hallazgos similares acaecidos en sitios como Hochdorf, Herbertingen o Igersheim (Koch, 1999: 147ss, figs. 153-154; lám. 11).

Para el tema de los alamares hispánicos ya Schüle señaló (con gran sorpresa) el extraordinario parecido del ejemplar de Carmona con las tipologías propias del Hallstatt B, así como con una serie de elementos similares que aparecen en depósitos del Bronce Final francés de la misma época (1969: 192). Pero los alamares andaluces son más tardíos y los pasadores presentes en los depósitos franceses (Coffyn et alii, 1981) no han aparecido hasta la fecha en territorio peninsular. Por eso no es posible verificar el uso de estos utensilios metálicos con anterioridad a la Edad del Hierro.

Otra posibilidad es que el sistema de cierres de alamar, por su sencillez, fuera usado de manera habitual en muchas de culturas de Europa y el Mediterráneo realizado sobre soportes perecederos, como la madera o el hueso, que no se han conservado. Y que solo en algunas zonas se dignificara su uso fundiéndolos (o forjándolos) en metal para los correajes de los carros de parada de la Edad del Hierro.

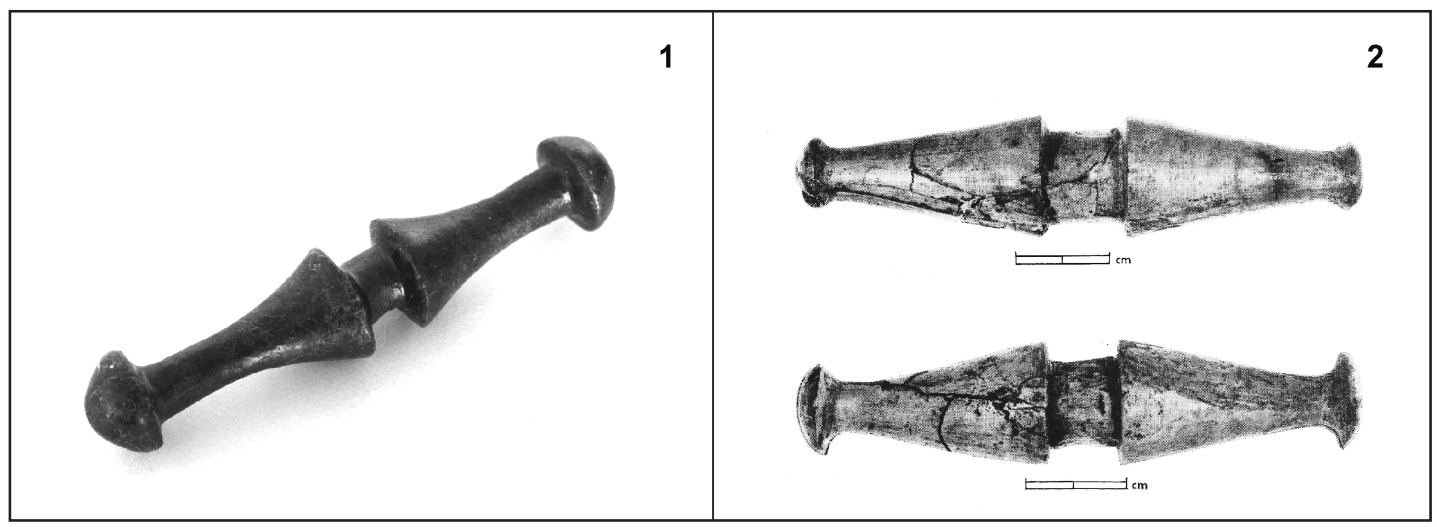

Figura 11. Pasadores o alamares bicónicos. 1. Ejemplar de bronce de época romana procedente de Mérida, foto MNAR-Ministerio de Cultura; 2. Elementos similares de marfil procedentes de la tumba 79 de Salamina de Chipre (siglo VIII a.C.), s. Karageorghis 1973-74.

En cualquier caso, no parece, fácil de resolver y, desde luego, excede las pretensiones de este trabajo, el tema del origen (temporal y cultural) del uso de estos pertrechos en la protohistoria peninsular, aunque probablemente su empleo sobre soportes perecederos estuviera mucho más extendido de lo que los actuales datos dejan entrever. Del éxito de este simple sistema de agarre y sujeción, por contra, da fe la continuidad de su empleo hasta, prácticamente, nuestros días.

En este sentido y, aunque el tema de este trabajo se ciña a la Edad del Hierro, me gustaría finalizar este apartado refiriéndome a un tipo de objetos característicos y abundantes en época romana que deben de haber marcado la continuidad de utensilios semejantes a lo largo de este período. Se trata de unos artefactos de bronce confeccionados sobre una barra maciza de tendencia bicónica que se estrecha por su parte central (donde, seguramente se instalaría la correa vuelta y cosida sobre si misma) y que se ensanchan por los extremos (Fig. 11.1). 
Es un tipo frecuente en yacimientos con horizontes romanos, donde suelen ser reconocidos con la denominación genérica de pasadores (Aurrecoechea, 2007: 342-343). En algunos contextos cerrados de época tardía han aparecido asociados a arreos ecuestres habiéndose propuesto para ellos reconstrucciones no alejadas a la que aquí planteo (Caballero, 1974: 104105), aunque otras veces, curiosamente, se los ha identificado con topes de camas de bocados de caballo, reincidiendo, según mi opinión, en el error que ha aquejado al estudio de sus congéneres protohistóricos durante décadas. La forma de esos alamares romanos de bronce aparece ya reflejada sobre piezas análogas de marfil halladas en tumbas del Chipro Arcaico I (considerablemente más antiguas, por tanto) de la necrópolis real de Salamina de Chipre (Karageorghis, 1967: láms. XLV y CCIX, no 96; 1973-74: láms. LV y CCXXXVI, nos. 136-137), (Fig. 11.2), dando pábulo así a la posibilidad antes señalada del uso de distintos soportes para la fabricación de unos sencillos utensilios que se extendería a lo largo del tiempo, y que sólo en determinados contextos históricos se trasladarían al metal o a otros materiales "nobles".

\section{EVIDENCIA ICONOGRÁFICA}

Como complemento de este estudio sobre los alamares metálicos en la Edad del Hierro peninsular y su función en los correajes ecuestres de esta época, se puede intentar verificar el uso de estos utensilios a través de su posible representación en alguna figuración escultórica de este periodo, algo que, por motivos obvios, está vedado en el área centroeuropea, donde no existen manifestaciones iconográficas de similar formato.

Las representaciones de caballos no son especialmente abundantes en la gran plástica ibérica en relación a otras especies como leones o toros y, prácticamente, ninguna de las esculturas hasta ahora conocidas se ha interpretado como correspondiente a un animal de tiro (Chapa, 1985). Por otra parte, en los ejemplares que aparecen enjaezados, normalmente obras de formato menor, raramente se perciben detalles de esta naturaleza (ver, por ejemplo, Cuadrado, 1950).

Existe, sin embargo, una escultura que podría marcar una significativa excepción a esto y que hasta ahora ha sido escasamente considerada: el busto equino hallado en el Cortijo de La Covatilla (Marchena) y conservado en el Museo Arqueológico Provincial de Sevilla, que parece formar parte de una obra de mayor envergadura.

$\mathrm{Su}$ conocimiento bibliográfico es deficitario, pues cuando se realizó la primera de las publicaciones que lo han tratado, aún se hallaba empotrado en la fachada de una casa de la localidad de Marchena, quedando irremisiblemente oculta a la vista y a la investigación toda la parte trasera (Bandera, 1979-80: 391ss). Posteriormente se ha publicado una fotografía de la pieza ya extraída en el catálogo de una exposición sobre arqueología del Guadalquivir celebrada en Vitoria en 2004, donde, en escorzo, se muestra el lado izquierdo del animal, que es el que está más deteriorado (Fernández Gómez, 2004: fig. 50).

De cara a nuestros propósitos - y, bajo mi punto de vista, de cara también al conocimiento general de esta pieza-, los elementos más interesantes de la escultura, hasta ahora inéditos, están en el lado derecho del animal, en la parte que estaba encastrada y oculta a la vista (Fig. 12.1).

En esta zona, a la altura de la cruz y hasta la espalda, se dispone un elemento de forma curvada, acabado en un remate semicircular, que debe de ser interpretado como la representación de un yugo dorsal. La detección de este yugo en una escultura ecuestre de gran formato resulta un hecho ya de por sí destacable atendiendo a dos motivos principales. En primer lugar, por ser la primera (y hasta ahora única) vez que aparece un elemento claramente vinculado con el 


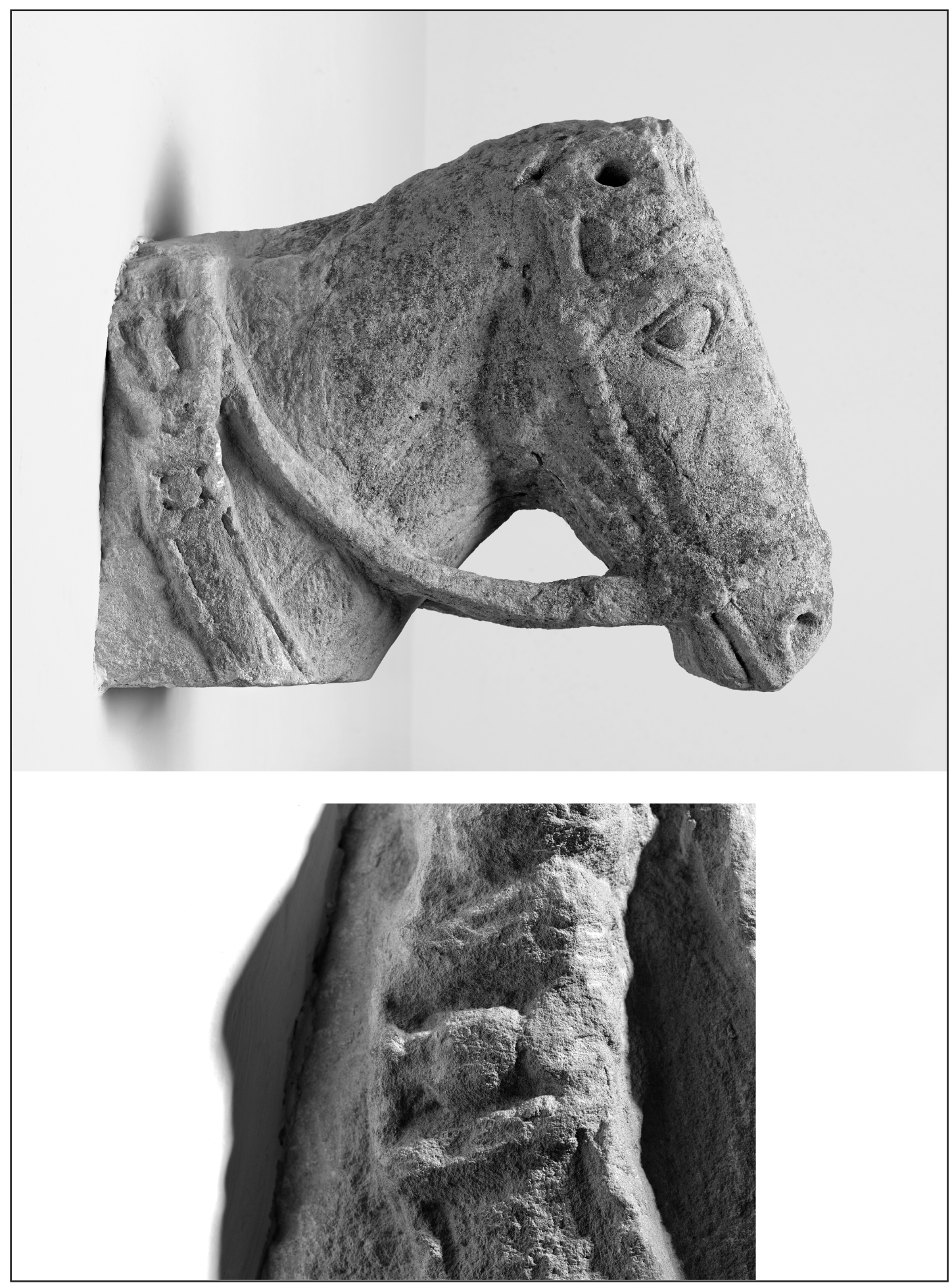

Figura 12. Escultura zoomorfa ibérica del Cortijo de la Covatilla (Marchena) y detalle de la zona del arnés. Museo Arqueológico Provincial de Sevilla. Fotos: Martín García Pérez. 
tiro en una escultura ibérica de estas dimensiones, con lo que probablemente estemos ante el primer grupo escultórico ibérico de gran formato que incorporaría un carro con sus caballos, con todo lo que ello implica en su vertiente técnica, simbólica, monumental, e ideológica. En segundo lugar, porque la disposición de este elemento, a la altura de la cruz, vendría a aportar un importante documento en el debate sobre el uso de yugos dorsales o de cuello en los carros de esta época de la protohistoria peninsular (para el tema, ver Spruytte, 1983).

Pero lo más significativo para este estudio son los elementos que se representan a continuación del yugo y que lo unen a una ancha banda pectoral, que discurre desde el hombro hasta el límite inferior, donde el bloque pétreo aparece regularmente cortado. En esta zona se ha trabajado una especie de anilla de contorno cuadrado de cuyo interior sobresale un elemento en el que, a pesar de las limitaciones de la representación, se reconoce la silueta casi inconfundible de uno de nuestros alamares. El objeto, formado por un cuerpo central elipsoidal y dos extensiones cónicas (al modo de un carrete) aparece encajado en el marco cuadrado, pero lo sobremonta por sus lados verticales, evidenciando así, con cierto grado de naturalismo, el sistema de ajuste y cierre del yugo al pectoral (Fig. 12.2).

La identificación de uno de estos alamares formando parte del mecanismo de cierre de un yugo, representado sobre una escultura ibérica equina, contribuye a verificar la utilización de que este tipo de utensilios fue objeto en la protohistoria europea. La localización de esta escultura en el Valle del Guadalquivir permite confirmar, además, el uso de alamares rectos en esta zona de la Península Ibérica en las últimas fases de la Segunda Edad del Hierro, conforme a la cronología que se ha propuesto para esta imagen (Bandera, 1979-80: 397). La situación de los ejemplares peninsulares más antiguos — los de La Joya y Acebuchal— en una zona no muy alejada de este hallazgo evidencian la continuidad del uso de este simple mecanismo de cierre en la talabartería del suroeste peninsular a lo largo de más de medio milenio.

\section{CONCLUSIONES}

En este trabajo se ha examinado un tipo de artefacto metálico constituido por un cuerpo central perforado y unos brazos rectos o curvos que aparece en varios contextos de la Protohistoria hispánica, comúnmente relacionados con atalajes ecuestres.

Las unidades conocidas permiten testimoniar, aparte de su condición de objeto típico, su uso extendido a lo largo de toda la Edad del Hierro por distintas zonas del territorio peninsular. En este escenario presentan comportamientos regionales y cronológicos significativos, si bien, en esta ocasión, me he detenido en examinar sobre todo sus aspectos funcionales.

De su estudio morfológico y contextual, así como de los múltiples paralelos europeos que presenta en las culturas de Hallstatt y La Tène, donde suelen aparecer vinculados a los sistemas de tracción de vehículos funerarios, se deduce que no se trata de camas laterales de bocados de caballo, como había venido proponiéndose para ellos de manera sistemática en la literatura arqueológica española. Al contrario, parece tratarse de elementos que se integran en los sistemas de cierre de los correajes que unen los animales con los yugos o con otros elementos del atalaje ecuestre, como pretales, gualdrapas, etc.

Este sistema de cierre estaría formado por una simple barra perforada y sujeta en su parte central por una correa, que pasa por una anilla u ojal donde quedaría aprisionada.

La escultura ibérica del Cortijo de Las Covatillas (Marchena, Sevilla), podría estar representando uno de estos cierres aplicado al yugo de un carro.

De las múltiples denominaciones que se les pueden aplicar a estos útiles (presillas, botones, agarres...), he propuesto la de 'alamar' recogida en el diccionario de la RAE y utilizada 
específicamente para el sistema de abotonadura constituido por un pasador transversal rígido (como el que usan las populares trencas), que es el que más se aproxima al mecanismo de cierre que representan los artefactos aquí tratados.

De este modo, se define y se caracteriza funcionalmente un tipo de objeto arqueológico específico dentro del utillaje metálico que integra la talabartería ibérica del Primer Milenio a.C.

Las fuertes analogías que presentan estos alamares hispánicos con sus congéneres europeos, desde una época tan temprana como la que marcan los ejemplares orientalizantes de La Joya, abren una serie de interrogantes que afectan al tema de la vinculación cultural del atalaje ecuestre, de los sistemas de monta y doma y de los carros usados en la Península Ibérica durante el I Milenio a.C. Unas cuestiones para las que la arqueología española adolece aún de un considerable desfase respecto de lo que se conoce de otras zonas de Europa y del Mediterráneo antiguo.

\section{AGRADECIMIENTOS}

Deseo expresar mi agradecimiento a las siguientes personas: Guillermo Kurtz (Museo Arqueológico Provincial de Badajoz); Ana Navarro, Juan Ignacio Vallejo y Julia Herce (Museo Arqueológico Provincial de Sevilla); Alicia Rodero y Javier Rodrigo (Museo Arqueológico Nacional); Ignacio Rodríguez Temiño (Conjunto Arqueológico de Carmona); Martín García Pérez (Fotógrafo) y Teresa García. Igualmente quiero manifestar la deuda de este trabajo con los profesores A. Lorrio (Universidad de Alicante) y M. Torres (Universidad Complutense de Madrid), que tuvieron la oportunidad de leer el manuscrito antes de su edición definitiva, aportando datos y sugerencias que lo han enriquecido de manera importante.

\section{BIBLIOGRAFÍA}

Almagro-Gorbea, M. y Torres, M. (1999): Las fibulas de jinete y de caballito. Aproximación a las élites ecuestres y su expansión en la Hispania céltica. Zaragoza.

Aurrecoechea, F. (2007): “Arneses equinos de época romana en Hispania”. Metalistería de la Hispania Romana. Sautuola 13. Santander: 321-344.

Bandera, M.L. de la (1979-80): "Nuevas figuras zoomorfas del Bajo Guadalquivir". Habis 10-11: 391400.

Blech, M. (2003): "Elementos de atalaje de Cancho Roano". Cancho Roano IX. Los materiales arqueológicos II (Celestino Pérez, S. ed.). Badajoz: 159-192.

Bonsor, G. (1931): An archaeological Sketch-book of the Roman Necropolis at Carmona. Nueva York.

Brailsford, J.W. (1975): “The Polden Hill Hoard, Somerset”. Proceedings of the Prehistoric Society 41: 222-234.

Brattinga, J. (2012): Two Bridles and a Yoke. A new Study into the Horse Gear from the Chieftain's Burial of Oss (Tesis de Máster, Universidad de Leiden). Leiden.

Caballero, L. (1974): La necrópolis tardorromana de Fuentespreadas (Zamora): un asentamiento en el Valle del Duero. Excavaciones Arqueológicas en España 80. Madrid.

Cabré, J. (1930): Excavaciones arqueológicas en la necrópoli celtibérica del Altillo del Cerropozo, Atienza (Guadalajara), practicadas bajo la dirección de Don Juan Cabré con la cooperación de Don Justo Juberías. Memorias de la Junta Superior de Excavaciones y Antigüedades 121. Madrid.

Cabré J. (1932): Excavaciones en las Cogotas, Cardeñosa (Ávila) II. La Necrópoli. Memorias de la Junta Superior de Excavaciones y Antigüedades 120. Madrid.

Cabré, J., Cabré, E. y Molinero, A. (1950): El castro y la necrópolis del hierro céltico de Chamartín de la Sierra (Avila). Acta Arqueológica Hispánica V. Madrid.

Cañal, C. (1894): Sevilla Prehistórica. Yacimientos prehistóricos de la Provincia de Sevilla. Sevilla. 
Coffyn, A., Gómez de Soto; J. y Mohen, J.P. (1981): L’Apogée du Bronze Atlantique: le dépôt de Vénat. París.

Cuadrado, E. (1950): (1950): Excavaciones en el santuario ibérico de El Cigarralejo (Mula, Murcia). Informes y Memorias de la Comisaría de Excavaciones 21. Madrid.

Chapa, T. (1985): La escultura ibérica zoomorfa. Madrid.

Fernández Gómez, F. (1986): Excavaciones arqueológicas en el Raso de Candeleda. Ávila.

Fernández Gómez, F. (2004): Arqueología del Valle del Guadalquivir. De la Prehistoria a Roma (Catálogo de la exposición celebrada en Vitoria). Córdoba.

Garrido, J.P. y Orta, E.M. (1978): Excavaciones en la necropolis de "La Joya", Huelva, II. 3 $3^{a}, 4^{a}$ y $5^{a}$ Campañas. Ecvavaciones Arqueológicas en España 96. Madrid.

Gomes, M.V. (2001): "Divinidades e santuarios púnicos, ou de influencia púnica, no sul de Portugal". Os púnicos no extremo occidente. Actas del Coloquio de Lisboa. Lisboa: 99-148.

Hoppe, M. (1986): Die Grabfunde der Hallstattzeit in Mittelfranken. Materialhefte zur Bayerischen Vorgeschichte A-55. Kallmünz.

Jimenez Ávila, J. (1999): La Toréutica orientalizante en la Península Ibérica (700-550 a. C.) (Tesis doctoral inédita, Universidad de Extremadura). Cáceres.

Jimenez Ávila, J. y Muñoz, K. (1997): "Pasarriendas de bronce en la Protohistoria peninsular: a propósito del hallazgo del Soto del Hinojar-Las Esperillas (Aranjuez, Madrid)". Cuadernos de Prehistoria y Arqueología de la UAM 24: 119-158.

Karageorghis, V. (1967): Excavations in the Necropolis of Salamis I. Nicosia.

Karageorghis, V. (1973-74): Excavations in the Necropolis of Salamis III. Nicosia.

Koch, J.K. (1999): Der Wagen und das Pferdegeschirr aus dem späthallstattzeitlichen Fürstengrab von Eberdingen-Hochdorf (Kr. Ludwigsburg) (Tesis doctoral, Universidad Christian-Albrechts). Kiel.

Koch, J.K. (2004): "Ein Pferd für Gunzenhausen. Die Rekonstruktion eines Ha-Czeitlichen Pferdegeschirres". Miszellen zur Eisen- und Römerzeit für Prof. Dr. Sabine Rieckhoff von ihren Mitarbeitern und Schülern. Leipziger online-Beiträge zur Ur- und Fruhgeschichtlichen Archäologie 15: 29-31.

Koch, J.K. (2006): Hochdorf VI: der Wagen und das Pferdegeschirr aus dem späthallstattzeitlichen Fürstengrab von Eberdingen-Hochdorf (Kr. Ludwigsburg). Forschungen und Berichte zur Vor- und Frühgeschichte in Baden-Württemberg 89. Stuttgart.

Kossack, G. (1954): "Pferdegeschirr aus Gräbern der älteren Hallstattzeit Bayerns". Jahrbuch des Römisch-Germanischen Zentralmuseums 1: 111-178.

Kurtz, W.S. (1986-87): "Los arreos de caballo en la necrópolis de Las Cogotas (Cardeñosa, Ávila)". Zephyrvs XXXIX-XL: 59-472.

Kurtz, W.S. (1987): La necrópolis de las Cogotas. Volumen I: Ajuares. Revisión de los materiales de la necrópolis de la Segunda Edad del Hierro en la Cuenca del Duero (España). B.A.R. International Series 344. Oxford.

Lobo del Pozo, M. " (2000): "Arreos de caballo. El caballo en la Celtiberia". Tiermes V. Carratiermes, Necrópolis Celtibérica. Arqueología en Castilla y León - Memorias 9. Valladolid: 70-90.

Lorrio, A. (1997): Los Celtiberos. Complutum Extra 7. Madrid

Lorrio, A. (2007): "Historiografía y nuevas interpretaciones: la necrópolis de la Edad del Hierro de Haza del Arca (Uclés, Cuenca)". XXVI Congreso Nacional de Arqueología. Coesaraugusta 78: 251-278

Lorrio, A. y Sánchez de Prado, M.D. (2009): La necrópolis celtibérica de Arcóbriga (Monreal de Ariza, Zaragoza). Caesaraugusta 80. Zaragoza.

Maluquer de Motes, J. (1981): El Santuario Protohistórico de Zalamea de la Serena, Badajoz. 19781981. Programa de Investigaciones Protohistóricas IV. Barcelona.

Maluquer de Motes, J. (1983): El Santuario Protohistórico de Zalamea de la Serena, Badajoz. 19811982. Programa de Investigaciones Protohistóricas V. Barcelona.

Pare, C.F.E. (1992): Wagons and Wagon-Graves of the Early Iron Age in Central Europe. Oxford Committee for Archaeology - Monographs 35. Oxford.

Piggott, S. (1983): The earliest wheeled transport: from the Atlantic Coast to the Caspian Sea. Londres.

Quesada, F. (2005): "El gobierno del caballo montado en la antigüedad clásica con especial referencia al caso de Iberia. Bocados, espuelas y la cuestión de la silla de montar, estribos y herraduras". Gladius, XXV: $97-150$ 
Quintero, P. (1913): Uclés, Excavaciones efectuadas en distintas épocas y noticia de algunas antigüedades. Segunda parte. Cádiz.

Sanz, C. (1997): Los Vacceos: cultura y ritos funerarios de un pueblo prerromano del valle medio del Duero. La necrópolis de Las Ruedas, Padilla de Duero (Valladolid). Arqueología en Castilla y León - Memorias 6. Salamanca.

Spruytte, J. (1983): Early Harness Systems. Londres.

Schüle, W. (1969): Die Meseta-Kulturen der Iberischen Halbinsel. Madrider Forschungen 3. Berlín.

Trachsel, M. (2004): Untersuchungen zur relativen und absoluten Chronologie der Hallstattzeit. Universitätsforschungen zür Prähistorischen Ärchäologie 104. Bonn.

Van der Vaart-Verschoof, S. (2011): Hail to the chieftain. A detailed examination of grave goods from Dutch chiefly burials and their role in funerary rituals during the Hallstatt Period (Tesis de Máster, Universidad de Leiden). Leiden.

Recibido: $22 / 09 / 14$

Aceptado: 24/05/15 